OPEN ACCESS

Edited by:

Karl-Josef Dietz,

Bielefeld University, Germany

Reviewed by:

Kyung-Min Kim

Kyungpook National University,

South Korea

Xiuli Hu,

Henan Agricultural University, China

${ }^{*}$ Correspondence:

Michael Riemann

michael.riemann@kit.edu

Specialty section:

This article was submitted to

Plant Abiotic Stress,

a section of the journal

Frontiers in Plant Science

Received: 30 June 2017 Accepted: 20 October 2017

Published: 10 November 2017

Citation:

Dhakarey R, Raorane $M L$, Treumann A, Peethambaran PK,

Schendel RR, Sahi VP, Hause B,

Bunzel M, Henry A, Kohli A and Riemann M (2017) Physiological and Proteomic Analysis of the Rice Mutant cpm2 Suggests a Negative Regulatory

Role of Jasmonic Acid in Drought

Tolerance. Front. Plant Sci. 8:1903.

doi: 10.3389/fpls.2017.01903

\section{Physiological and Proteomic Analysis of the Rice Mutant cpm2 Suggests a Negative Regulatory Role of Jasmonic Acid in Drought Tolerance}

\author{
Rohit Dhakarey ${ }^{1,2}$, Manish L. Raorane ${ }^{1,2}$, Achim Treumann ${ }^{3}$, \\ Preshobha K. Peethambaran ${ }^{1}$, Rachel R. Schendel ${ }^{4}$, Vaidurya P. Sahi ${ }^{1}$, Bettina Hause ${ }^{5}$, \\ Mirko Bunzel ${ }^{4}$, Amelia Henry ${ }^{2}$, Ajay Kohli ${ }^{2}$ and Michael Riemann ${ }^{1 \star}$ \\ ${ }^{1}$ Molecular Cell Biology, Institute of Botany, Karlsruhe Institute of Technology, Karlsruhe, Germany, ${ }^{2}$ International Rice \\ Research Institute, Los Baños, Philippines, ${ }^{3}$ Newcastle University Protein and Proteome Analysis, Newcastle University, \\ Newcastle Upon Tyne, United Kingdom, ${ }^{4}$ Department of Food Chemistry and Phytochemistry, Institute of Applied \\ Biosciences, Karlsruhe Institute of Technology, Karlsruhe, Germany, ${ }^{5}$ Cell and Metabolic Biology, Leibniz Institute of Plant \\ Biochemistry, Halle, Germany
}

It is widely known that numerous adaptive responses of drought-stressed plants are stimulated by chemical messengers known as phytohormones. Jasmonic acid (JA) is one such phytohormone. But there are very few reports revealing its direct implication in drought related responses or its cross-talk with other phytohormones. In this study, we compared the morpho-physiological traits and the root proteome of a wild type (WT) rice plant with its JA biosynthesis mutant coleoptile photomorphogenesis 2 (cpm2), disrupted in the allene oxide cyclase $(\mathrm{AOC})$ gene, for insights into the role of JA under drought. The mutant had higher stomatal conductance, higher water use efficiency and higher shoot ABA levels under severe drought as compared to the WT. Notably, roots of cpm2 were better developed compared to the WT under both, control and drought stress conditions. Root proteome was analyzed using the Tandem Mass Tag strategy to better understand this difference at the molecular level. Expectedly, AOC was unique but notably highly abundant under drought in the WT. Identification of other differentially abundant proteins (DAPs) suggested increased energy metabolism (i.e., increased mobilization of resources) and reactive oxygen species scavenging in cpm2 under drought. Additionally, various proteins involved in secondary metabolism, cell growth and cell wall synthesis were also more abundant in cpm2 roots. Proteome-guided transcript, metabolite, and histological analyses provided further insights into the favorable adaptations and responses, most likely orchestrated by the lack of JA, in the cpm2 roots. Our results in cpm2 are discussed in the light of JA crosstalk to other phytohormones. These results together pave the path for understanding the precise role of JA during drought stress in rice.

\footnotetext{
Keywords: jasmonates, rice, drought, root, proteomics, phytohormones, cross-talk
} 


\section{INTRODUCTION}

Rice serves as the staple food for more than $50 \%$ of world's population. It is cultivated in over a hundred countries, with a total harvested area of $\sim 163.3$ million hectares, with a produce of more than 749.7 million tons annually (GRiSP, 2013; FAO, 2016). In comparison to other crops, rice production is highly waterintensive and almost $30.9 \%$ of the total rice area of the world is through rainfed agriculture (Wassmann et al., 2009; Dixit et al., 2014). As per an estimate, nearly 2,500 liters of water is needed to give rise to $1 \mathrm{~kg}$ of rice, and irrigated rice consumes around $34-43 \%$ of the world's total irrigation water (Bouman et al., 2007). Hence water deficit or drought is said to be the most calamitous form of abiotic stress for rice and can result in yield losses of 15$50 \%$, depending on the severity and timing of stress (Srividhya et al., 2011). Globally, drought stress leads to an estimated 18 million tons of rice yield reduction per year (O'Toole, 2004).

Drought stress affects rice during all growth stages (Venuprasad et al., 2008). Development of droughttolerant, higher-yielding varieties suitable for water-limiting environments is a major challenge for improvement of rice production and in turn for increasing food security. The development of such varieties can be fast-tracked through the knowledge of the physiological and molecular genetic mechanisms underpinning drought tolerance.

Growth regulators also known as phytohormones orchestrate plant responses to growth, development, and external stimuli (Wolters and Jurgens, 2009). These compounds are synthesized through various biosynthetic processes and can function either at the site of their genesis or be translocated to function somewhere else in the plant. They often quickly modify gene expression by instigating or blocking the degradation of transcriptional regulators via the ubiquitin-proteasome system (Santner and Estelle, 2010). Abscisic acid (ABA)-mediated signaling and ABAresponsive genes is one of the most investigated hormonal responses of plants to abiotic stress, especially in drought (Tuteja, 2007; Sreenivasulu et al., 2012). The role of ABA in the regulation of stomata opening/closure and other critical responses to abiotic stress is quite established (Mittler and Blumwald, 2015). Drought and other stresses such as, salinity result in an increased content of ABA, which orchestrates extensive changes in the expression of genes regulated by or responsive to ABA (Shinozaki and Yamaguchi-Shinozaki, 2007). However, such a change in a single phytohormonal pathway usually affects other phytohormonal pathways as well, and the resulting crosstalk contributes to the overall response of plant to abiotic stress (Kohli et al., 2013). Jasmonates (i.e., jasmonic acid, its precursors, and direct derivatives) are critical components of such crosstalk (Riemann et al., 2015).

The phytohormone jasmonic acid (JA) and its metabolically active derivatives like methyl-jasmonate and JA-Isoleucine (JAIle) are crucial signaling molecules, which actively engage in plant responses to various biotic as well as abiotic stresses (Wasternack, 2007; Balbi and Devoto, 2008). In the JA biosynthesis pathway, plastidial 13-lipoxygenases (13-LOX) act on linolenic acid to convert it to 13S-hydroperoxyoctadecatrienoic acid (13-HPOT). Allene oxide synthase (13-AOS) and allene oxide cyclase (AOC) act in combination to synthesize cis-12-oxophytodienoic acid (OPDA). OPDA is then transported into peroxisomes where it is reduced by OPDA reductase (OPR). Subsequently it is converted into JA by three $\beta$-oxidation steps (Wasternack and Hause, 2013). An important step in jasmonate biosynthesis is regulated by AOC, which is encoded by a four membered small gene family in Arabidopsis thaliana. In A. thaliana, AOC functions as homoor hetero-trimer (Hofmann et al., 2006; Stenzel et al., 2012; Otto et al., 2016). In rice, however, this enzyme is encoded by a single copy gene (Dhakarey et al., 2016).

There is limited information on the role of jasmonates in the response of rice to drought (Liu et al., 2015; Riemann et al., 2015; Dhakarey et al., 2016). In this report, a JA synthesis mutant called coleoptile photomorphogenesis 2 (cpm2) was used to understand the role of JA on rice physiological and molecular responses to drought. It carries an 11 bp deletion within the first exon of AOC (Riemann et al., 2013; Dhakarey et al., 2016). Comparative studies between the WT and the mutant for differences in drought response were undertaken at the vegetative growth stage, since cpm 2 is male sterile. Assessment of drought response was conducted on a set of morphological parameters and root proteome. The differentially abundant proteins (DAPs) in the root proteome study were related to various pathways and processes. Additional histological and metabolite analysis guided by the DAPs supported the observation that cpm2 was better adapted to cope with drought stress. This leads to the proposition that jasmonates might be negative regulators of drought tolerance.

\section{MATERIALS AND METHODS}

\section{Plant Growth and Drought Stress Conditions for Phenotyping and Stomatal Conductance}

Oryza sativa L. ssp. japonica cv. Nihonmasari serving as the wild type (WT) and the cpm2, the JA biosynthesis mutant generated in the same background (Riemann et al., 2013), were used in this whole study. Dehusked caryopses were surface sterilized as per Hazman et al. (2015), were then sown on $0.5 \%$ phytoagar medium (Duchefa, Netherlands) and kept for 14 days in a culture room at $25^{\circ} \mathrm{C}$ and continuous light of $120 \mu \mathrm{mol}$ quanta $\mathrm{m}^{-2} \mathrm{~s}^{-1}$. On the 14 th day, 10 selected seedlings of each genotype were transferred in sand filled pots, kept for another 2 weeks under short-day conditions of $10 \mathrm{~h}$ light at $28^{\circ} \mathrm{C}$ and $280 \mu \mathrm{mol}$ quanta $\mathrm{m}^{-2} \mathrm{~s}^{-1}$, followed by $14 \mathrm{~h}$ darkness at $22^{\circ} \mathrm{C}$ in a phytochamber (BBC York, Mannheim, Germany). Plants were kept well-watered and provided once a week with fertilizers "Wuxal-TopN" (N $141.6 \mathrm{~g} / \mathrm{l}, \mathrm{P}_{2} \mathrm{O}_{5} 47.2 \mathrm{~g} / \mathrm{l}, \mathrm{K}_{2} \mathrm{O} 70.8 \mathrm{~g} / \mathrm{l}, \mathrm{B}$ $0.118 \mathrm{~g} / \mathrm{l}, \mathrm{Cu} 0.047 \mathrm{~g} / \mathrm{l}, \mathrm{Fe} 0.236 \mathrm{~g} / \mathrm{l}, \mathrm{Mn} 0.141 \mathrm{~g} / \mathrm{l}$, Mo 0.012 $\mathrm{g} / \mathrm{l}, \mathrm{Zn} 0.047 \mathrm{~g} / \mathrm{l}$ ) and "Wuxal-Super" (N $99.2 \mathrm{~g} / \mathrm{l}, \mathrm{P}_{2} \mathrm{O}_{5} 99.2 \mathrm{~g} / \mathrm{l}$, $\mathrm{K}_{2} \mathrm{O} 74.4 \mathrm{~g} / \mathrm{l}$, B $0.124 \mathrm{~g} / \mathrm{l}, \mathrm{Cu} 0.049$ g/l, Fe 0.248 g/l, Mn 0.148 g/l, Mo 0.012 g/l, Zn 0.049 g/l (Manna, Ammerbuch-Pfaffingen, Germany). In the phytochamber, five seedlings of each genotype (aged 28 days) were subjected to drought stress for 4 days by withholding water followed by rewatering for 2 days; control plants were maintained in parallel. Stomatal conductance was 
measured with a portable-type porometer (Decagon Devices, USA) for 4 consecutive days after withholding water and for 2 consecutive days after rewatering at noon on the youngest fully-expanded attached leaf on the plants of the same age (five sub-replicates).

\section{Root Architecture and Water Use Efficiency (WUE) Analysis Setup}

Root architecture and WUE experiments were conducted in the greenhouse at the IRRI. For the root architecture study, seedlings germinated as described above were planted in small $(40 \mathrm{~cm}$ height, $4 \mathrm{~cm}$ in diameter, $502.6 \mathrm{~cm}^{3}$ ) cylinders filled with dry, sterilized and sieved soil to a bulk density of $1.1 \mathrm{~g} \mathrm{~cm}^{-3}$. Soil moisture treatments of control (100\% of field capacity), $75 \%$ of field capacity and dry-down to $50 \%$ of field capacity were applied as described by Henry et al. (2015). Five replicates of each genotype were planted for each soil moisture treatment. Plants were scouted regularly to guard against insect or pathogen infestations; sticky fly paper traps were also suspended between the cylinders to keep away insects. Roots were harvested, subjected to washing in order to remove the dirt and soil prior to their storage in $75 \%$ ethanol for further analysis using WinRHIZO (Régent Instruments, Quebec, Canada).

Similarly, for apparent WUE measurement, WT, and cpm2 seedlings were planted in large cylinders $(95 \mathrm{~cm}$ in height, $20 \mathrm{~cm}$ in diameter, 29.81) which were filled with dried soil previously brought from an upland IRRI farm and were arranged in randomized complete block design. Additional sterilized soil was filled at the top of each cylinder. Ten plants of each genotype were planted in 20 large cylinders placed inside a concrete tank ( $1.35 \mathrm{~m}$ deep, $3.5 \mathrm{~m}$ wide, and $6.8 \mathrm{~m}$ in length) inside the naturally ventilated greenhouse. All cylinders were equally watered twice a day to keep them watered but not flooded. Complete fertilizer was also applied as per Kijoji et al. (2012) 1 day after transplanting Drought stress (DS) was imposed on five plants of each genotype at 32 days after sowing by draining water from the designated cylinders and by withholding further addition of water in them. The top of the cylinders were then covered with polythene sheets to curtail direct evaporation, so that only water loss by transpiration was measured. Remaining cylinders belonging to the control treatment were kept watered using the target weight to maintain the soil moisture level at field capacity, which was established by weighing at day 36 after sowing. DS cylinders were not watered for the remaining time. Digital imaging of shoots and weighing of each cylinder was performed three times per week using the system described by Kijoji et al. (2012) for 4 weeks after imposing drought stress. Using image $J$ software (NIH, USA) with an integrated macro language, leaf area was estimated from digital images and divided by the water uptake rate to calculate apparent WUE.

\section{Plant Materials, Growth, and Stress Conditions for Root Proteome, ABA, Cell Wall Metabolite, and Transcript Level Analysis}

Sampling material for experiments related to root proteome, transcript and selected metabolite analysis were raised in the naturally ventilated greenhouses at IRRI during the 2014 and 2015 dry season. WT and cpm2 seedlings generated as described above were then transferred to plastic pots $(20 \mathrm{~cm}$ in diameter) filled with autoclaved soil (previously collected from IRRI upland farm). All pots were equally watered by providing $200 \mathrm{ml}$ twice a day for 1 week and then separated into "control" and "stressed" categories. For the control treatment, plants were watered but not flooded, and their entire roots and shoots were sampled at day 22. For drought-stressed plants, watering was stopped to initiate moderate and severe stress condition. Volumetric soil moisture content (SMC) in the drought-stress treatment was monitored by ML3 Theta Probe soil moisture sensor (Delta-T Devices, London, UK; one per replicate). The entire root and shoot was sampled for "stressed" treatments as soon as SMC reached 30 and 15\% for moderate and severe stress, respectively, and were instantly frozen in liquid nitrogen. Soil particles were removed from the root samples prior to their storage in liquid nitrogen.

\section{Protein Extraction, Separation, Tryptic Digestion, and TMT Labeling}

Frozen root samples from WT and cpm2 were used for total protein extraction. Subsequently, a modified trichloroacetic acid (TCA, Merck, USA) method was used for protein extraction. Frozen root samples $(\sim 250 \mathrm{mg}$ ) were crushed to a fine powder in a pre-cooled mortar with liquid nitrogen. Afterwards, the powder was transferred to a $1.5 \mathrm{ml}$ pre-chilled Eppendorf tube and then following extraction procedure was performed: (i) 700 $\mu \mathrm{l}$ of freshly prepared $10 \%$ TCA in acetone with $0.07 \%$ DTT (DL-Dithiothreitol, Merck, USA) was added to the tubes. The tubes were then placed at $-80^{\circ} \mathrm{C}$ for $1 \mathrm{~h}$, and then centrifuged in a pre-cooled rotor at $13,000 \mathrm{~g}$ for $10 \mathrm{~min}$ at $4^{\circ} \mathrm{C}$ (Beckman Allegra 64R preparative centrifuge, USA). (ii) The supernatant was discarded and the pellet was re-suspended in $700 \mu l$ of freshly prepared pre-cooled $10 \%$ acetone with $0.07 \%$ DTT. The suspension was further stored at $-80^{\circ} \mathrm{C}$ for $30 \mathrm{~min}$, prior to centrifugation in a pre-cooled rotor at $13,000 \mathrm{~g}$ for $10 \mathrm{~min}$ at $4^{\circ} \mathrm{C}$. This step was repeated twice. The supernatant was discarded and the pellet was then air-dried for $45 \mathrm{~min}$ in a laminar hood at room temperature $\left(\sim 24^{\circ} \mathrm{C}\right)$. The resulting pellet was then re-suspended in $700 \mu \mathrm{l}$ solubilizing buffer containing $9 \mathrm{M}$ urea, 1\% DTT, 4\% CHAPS (3-[(3-Cholamidopropyl) dimethylammonio]-1-propane sulfonate), $35 \mathrm{mM}$ Tris base, $5 \mu \mathrm{M}$ EDTA (Ethylenediaminetetraacetic acid), $1 \mu \mathrm{M}$ PMSF (phenylmethylsulfonyl fluoride) and $10 \mu \mathrm{l}$ of protease inhibitor cocktail solution (Merck, USA). Afterwards, the samples were centrifuged at $13,000 \mathrm{~g}$ for $5 \mathrm{~min}$ at room temperature and the resulting supernatant with the proteins was collected into a clean Eppendorf tube. The proteins were run through SDS-PAGE under denaturing conditions (Laemmli, 1970). The subsequent in-gel digestions of proteins, TMT labeling and Nano-LC-MS/MS analysis were performed as previously published (Raorane et al., 2015a). For overview, refer to Figure S1.

\section{Protein Identification, Functional Annotation, and Evaluation}

Protein identification and their functional annotation was performed as described by Raorane et al. (2015a). For the proteins common to both WT and cpm 2 roots, a threshold of $\log$ ratio 1.0 
or greater (2-fold more) was used as a criterion for comparative abundance of the protein in one genotype. Conversely, proteins having log ratios lower than 1.0 (2-fold less) were considered comparatively less abundant.

\section{Quantitative Reverse Transcriptase PCR (qRT-PCR) Analysis of Selected Genes}

Primer3 was used for designing the primers (listed in Table S1) and the subsequent procedures related to RNA extraction; cDNA synthesis and qRT-PCR were performed as illustrated in Raorane et al. (2015b). OsCyclophilin-2 was employed as the housekeeping gene for all the qRT-PCR analysis (Pabuayon et al., 2016).

\section{Quantification of Endogenous ABA and Jasmonate Levels in Shoot and Root Samples}

$\mathrm{ABA}$ and jasmonates were quantified from shoot and root samples as described by Balcke et al. (2012). In brief, about $50 \mathrm{mg}$ of frozen plant material was homogenized and extracted with $500 \mu \mathrm{l}$ pure methanol supplied with $\left[{ }^{2} \mathrm{H}_{6}\right] \mathrm{ABA},\left[{ }^{2} \mathrm{H}_{5}\right]$ OPDA, $\left[{ }^{2} \mathrm{H}_{6}\right] \mathrm{JA}$, and $\left[{ }^{2} \mathrm{H}_{2}\right]$ JA-Ile (50 ng each) as internal standards. After centrifugation, the supernatant was diluted with 9 volumes of water and subjected to solid phase extraction on HR-XC (Chromabond, Macherey-Nagel) column. Elution was done with $900 \mu \mathrm{l}$ acetonitrile. Ten micro liter of the eluate was subjected to ultra-performance liquid chromatography-tandem mass spectrometry (UPLC-MS/MS) according to Balcke et al. (2012). The contents of ABA, OPDA, JA, and JA-Ile were calculated using the ratio of analyte and internal standard peak heights.

\section{Root Cell Wall Monosaccharides and Hydroxycinnamic Acids Analysis}

Sampling material grown at the IRRI greenhouses (for targeted metabolite analysis) was used for these measurements. Further milling of the frozen root samples was done to $<0.5 \mathrm{~mm}$ (IKA mill or porcelain mortar with dry ice). Milled samples were stored in the freezer $\left(-44^{\circ} \mathrm{C}\right)$ for subsequent monosaccharides and hydroxycinnamic acids analyses. Destarched cell wall material was isolated and purified (digestion with thermostable $\alpha$-amylase and amyloglucosidase and precipitation of nonstarch polysaccharides in $80 \%$ ethanol). Ester-linked oligoferulates (dimers and trimers) were quantified in the destarched cell wall material following alkaline hydrolysis $(2 \mathrm{M} \mathrm{NaOH}$, $18 \mathrm{~h}$ ), acidification, extraction with diethyl ether, and LC-ESIMS/MS separation and detection (negative ionization with triplequadrupole mass analyzer). Internal standard quantification was performed using 5-5-methyl-diferulic acid. Ester-linked monomeric trans-ferulic and trans-p-coumaric acids (FA and $p C A$ respectively) were also determined in the alkaline hydrolysates, but were detected and quantified via external curves using an inline UV detector (320 and $307 \mathrm{~nm}$ detection wave lengths for trans-ferulic and trans-p-coumaric acids respectively) coupled to the LC-MS/MS system. Monosaccharide analysis of the destarched cell wall material was performed after sulfuric acid hydrolysis using high-performance anion-exchange chromatography with pulsed amperometric detection (HPAECPAD) as described in Schäfer et al. (2016).

\section{Histology of Root Tissue}

WT and cpm2 seedlings were grown in a phytochamber (BBC York, Mannheim, Germany) as described above. Root samples were harvested for control and severe stress (SMC $15 \%)$ treatments. Using a hand microtome, thin sections of 25$30 \mu \mathrm{m}$ thickness were taken from the center of basal and axial ends of roots from WT and cpm2 plants grown normally and under drought stress conditions. Sections were stained in $1 \%$ $(\mathrm{w} / \mathrm{v})$ phloroglucinol in $18 \%$ hydrochloric acid $(\mathrm{HCl})$, mounted with water on a glass slide and observed using an Axioskop microscope (Zeiss GmbH, Jena, Germany) equipped with a 20x objective. Pictures were taken using a CCD camera (AxioCam, Zeiss) attached to the microscope.

\section{Statistical Analysis}

Representation of individual plants of a genotype within each sample and the number of replicates for each analysis/measurement are given in the figure legends. Student's $t$-test was performed for testing the statistical significance of the calculated mean values, with a significance level of $P \leq 0.05$ and subsequent graphs were plotted using GraphPad Prism version 7 (GraphPad Software, La Jolla California USA). The ASReml script was used as a repeated measures analysis across all dates for WUE using R v. 3.3.1 (R Core Team, 2016). The underlying statistical model was WUE $\sim$ Treatment + Genotype + DAS.

\section{RESULTS}

\section{Increased Adaptive Response of cpm2 Morpho-Physiology to Drought}

cpm2 and WT plants raised for 4 weeks were subjected to drought stress. After withholding water for 2 days, response to drought became apparent in the WT plants through leaf rolling, mainly in the upper reaches of the leaves, despite apparently stronger culms, compared to cpm2 (Figures S2A,B). At the end of day four, WT leaves developed symptoms of wilting. In contrast the upper reaches of the cpm2 leaves remained open and appeared turgescent while still the well-developed culm of the WT gave the impression of a stronger plant (Figures S2C,D). These initial results obtained with plants in the phytochamber were further confirmed by greenhouse studies in tropical latitudes.

The apparent adaptation of $c p m 2$ to drought was borne out by other parameters. For example, the $c p m 2$ plants had a higher water use efficiency (WUE) before drought stress was initiated as compared to WT ( 0.23 unit higher in cpm 2 in ASReml). However, with progressive drought stress, WUE in cpm2 plants was even higher than in those of WT ( 0.28 units higher in cpm 2 in ASReml) and the difference increased persistently till day 14 after the onset of drought (Figure 1). Consistently, the $p$-value for the genotype effect became lower under drought conditions as well.

Additionally, in 4 weeks old plants, similar stomatal conductance was observed for cpm2 and WT plants under control conditions (Figure 2A). However, under drought condition, the overall stomatal conductance in cpm2 showed less 
drastic decrease than in the WT (Figure 2B). Initially, during the first couple of days after the onset of drought conditions, stomatal conductance in WT showed significant increase compared to cpm2. However, at day three, the stomatal conductance for both the genotypes decreased significantly, however both maintained almost similar degree of conductance. From day four, the trend was reversed and stomatal conductance in cpm2 plants was

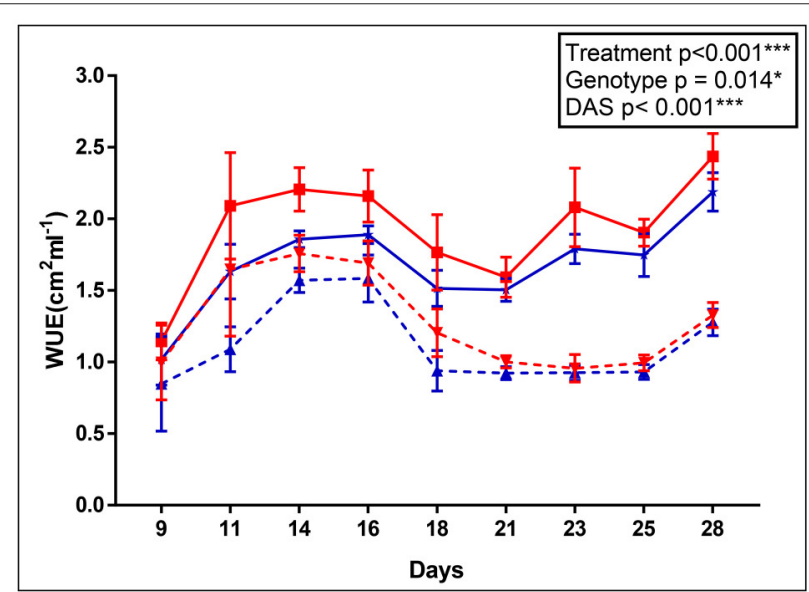

FIGURE 1 | Apparent water use efficiency (WUE) of wild type (WT) and cpm2. WT\& cpm2 plants were subjected to drought after 32 days of sowing by withholding water. Digital imaging of shoots was performed to estimate green leaf area which was later normalized by water uptake/day to calculate apparent WUE. Data is shown for 9, 11, 14, 16, 18, 21, 23, 25 and 28 days after imposing drought stress. The values presented are means \pm standard error(SE); $n=5$. WT and cpm2 are indicated by blue and red lines, respectively; whereas dotted and solid lines represent control and stress treatment, respectively. The $p$-value is indicated as determined by ASReml analysis. Significance levels are indicated as : ${ }^{*} P \leq 0.05 ;{ }^{* \star} P<0.001$.
2 -fold more than in WT plants (Figure 2B), which were almost wilting (Figure S2C). After re-watering, water levels in both sets of plants were replenished. One day after re-watering, cpm2 plants still exhibited higher stomatal conductance compared to the WT plants. However, stomatal conductance progressively increased in the WT plants after re-watering, till on day 6 it was more than that in the cpm2 plants (Figure $\mathbf{2 B}$ ).

In terms of drought responsive phytohormones, the $\mathrm{ABA}$ content is a measure of drought tolerance (Daszkowska-Golec, 2016; Negin and Moshelion, 2016). Under both the control and moderate stress conditions (SMC of 30\%), ABA content in the WT shoots was almost double that in cpm2 shoots. Under severe stress conditions (SMC of 15\%), ABA increased in both cpm2 and WT shoots. However, the increase in ABA content in cpm2 shoots was almost double that in the WT shoots (Figure 3A). In case of root ABA content, there were no significant changes in their levels in both the genotypes under control and moderate stress, however, during severe stress cpm2 had almost 1.5 fold induction in the ABA content as compared to the WT (Figure 3B).

As assessed through leaf rolling, WUE, stomatal conductance, and $\mathrm{ABA}$ content, these results clearly demonstrated cpm 2 to have an advantage over WT in coping with drought stress. An advantageous drought response of the aerial parts suggested that the roots of cpm 2 may also exhibit advantageous features as roots first sense and react to drought.

\section{The Root System of cpm2 Is Better Developed}

For the WT and cpm2 plants root growth was assessed under control and drought stress conditions. Nodal root length was reduced under severe drought by nearly $40 \%$ in the WT and by nearly $50 \%$ in cpm 2 compared to the control condition (Figure 4A). Lateral root length was reduced under drought in
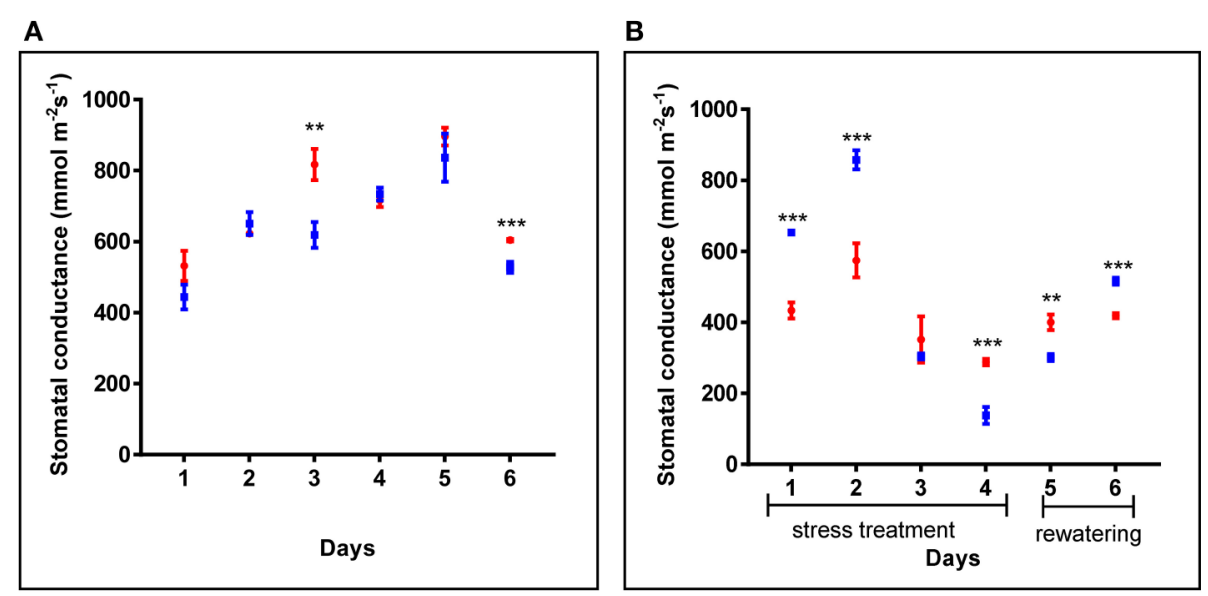

FIGURE 2 | Comparison of stomatal conductance of wild type (WT) and cpm2 in (A) control conditions and (B) under drought. Four-week-old WT and cpm2 plants were exposed to drought stress by withholding water for 4 days followed by re-watering for 2 days. Under control conditions, WT and cpm 2 maintained almost a steady state throughout the course of experiment, while cpm2 maintained lower stomatal conductance as compared to WT under drought. The values presented are means \pm standard error (SE); $n=5$. Blue and red symbols indicate WT and $c p m 2$, respectively. Stars $\left(^{\star *}\right.$ and $\left.{ }^{* \star *}\right)$ denote statistical significance $(P \leq 0.01$, and $P \leq$ 0.001), respectively, between the two genotypes in a Student's $t$-test. 

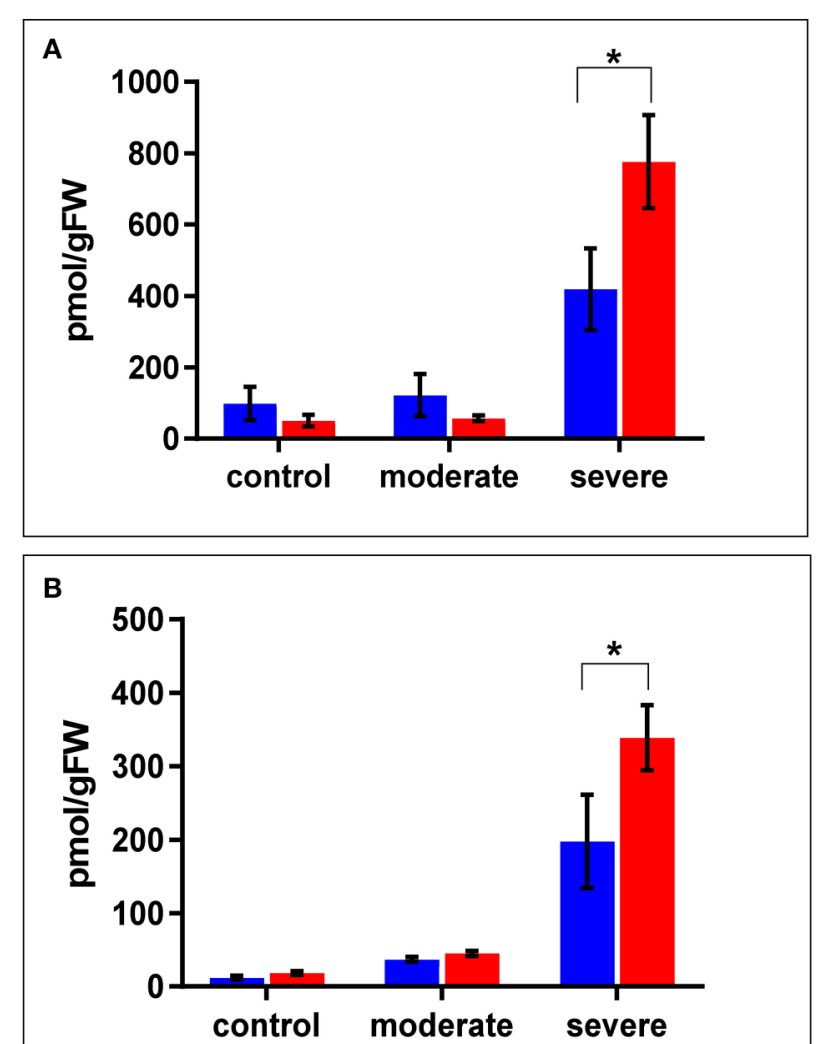

FIGURE 3 | The level of ABA (Abscisic Acid) in (A) shoots and (B) roots of cpm2 and wild type (WT) under control, moderate, and severe drought stress. Three-week-old WT and cpm2 seedlings were either kept well-watered, and the control plants were sampled at day22, or watering was stopped to initiate moderate and severe stress conditions. Shoot and root samples were harvested in control, moderate and severe stress condition, respectively. WT and cpm2 are represented by blue and red bars, respectively. Data represents mean value \pm standard error (SE); $n=5$. Star $\left(^{*}\right)$ denote statistical significance $(P \leq 0.05)$, respectively, between the two genotypes in a Student's $t$-test.

both plant types by nearly $50 \%$ compared to control condition, whereby severe drought stress inflicted more drastic reduction than moderate stress (Figure 4B). Thus, $c p m 2$ did not exhibit a comparative advantage in nodal and lateral root length under severe drought. A similar profile was observed for other root traits such as, the sum of all root lengths (Figure 4C) and the total number of root forks and tips (Figures 4D,E). However, in all these aforementioned root traits a significant advantage was observed in cpm2 plants under control conditions and this advantage was further maintained during moderate stress conditions compared to WT. Also, in cpm2, maximum root depth (Mrd) exceeded that of the WT in all the treatments (Figure 4F). However, this difference in Mrd between WT and cpm2 became smaller with increasing severity of drought stress. Under severe drought stress the difference was no longer statistically significant. These results highlighted that overall cpm2 exhibited a more branched root system than the WT both under control and drought conditions (Figure S3).

\section{Root Proteome Analysis Supports cpm2 Adaptation to Drought}

Root peptide extracts from cpm2 and WT plants under control and severe drought were subjected to mass spectrometry analysis using high-throughput Tandem Mass Tag (TMT) approach. Out of 15,172 spectra obtained in total, 13,485 referred 4,573 peptides. Of these, 4,194 hits were designated to unique peptides, which amounted to the combined identification of a total of 1,578 proteins in WT and cpm 2 roots. Out of these, 351 and 341 proteins were unique to $\mathrm{WT}$ and $c p m 2$ roots, respectively, whereas 443 proteins were common in both the genotypes (Figure 5A). However, the number of unique proteins with dependable quantitative estimates was 272 and 217 for WT and cpm2, respectively, and 319 as common proteins (Figure 5B). In order to filter out JA-dependent and -independent proteins, a comparison between control and drought conditions was carried out within one genotype (WT or $c p m 2$, respectively).

A wide range of isoelectric points (4.41-11.91) and molecular weights (4.4-236.7 kDa) implicated a dynamic range of proteins. Proteins from both the genotypes were assigned to 32 functional categories using MapMan (Thimm et al., 2004) as per the rice mapping file (Figure S4).

The AOC protein was highly abundant in WT but as expected, it was not found in cpm2 (Figure 6A). Lack of AOC protein was nevertheless not directly related to its transcript abundance. In fact, under moderate or severe drought, $A O C$ transcript was abundant in cpm2 as compared to the WT (Figure 6B). Under well-watered condition, the WT contained nearly 2 -fold more $A O C$ transcript than $c p m 2$. The $A O C$ transcripts in $c p m 2$ are thus either not translated, or the protein may have been highly unstable, and the mutational frame-shift in the coding sequence leading to an undesirable protein may account for that. In contrast to AOC, the oxo-phytodienoate reductase (OPR7), an enzyme operating downstream of AOC (Tani et al., 2007), was more abundant in $c p m 2$ under drought (Figure 6A). The OPR7 transcript levels were also observed to be significantly higher in WT than in cpm2. However, under moderate and severe drought stress no significant difference in the expression of $O P R 7$ was observed (Figure 6C).

Apart from such differences owing to the mutation, many proteins showed substantial up- or down-regulation (difference of $\log$ ratio of 1.0) and were classified as DAPs between the WT and the mutant plant. Several of such proteins could be assigned to categories responsive to drought. These categories, the genes therein and their protein abundance status in the WT and cpm2 are summarized in Table 1. The potential importance of such DAPs in the apparent adaptation of $c p m 2$ to drought is described in the "Discussion" section.

\section{Cell Wall Metabolite Analysis Supports Root Phenotype and Proteome-Based Inferences}

As mentioned above, cpm 2 root traits such as more branching, increased total root length and root depth exhibited a genotypic advantage which was maintained under stress. This was supported by root proteome-based information, mainly on the 
A

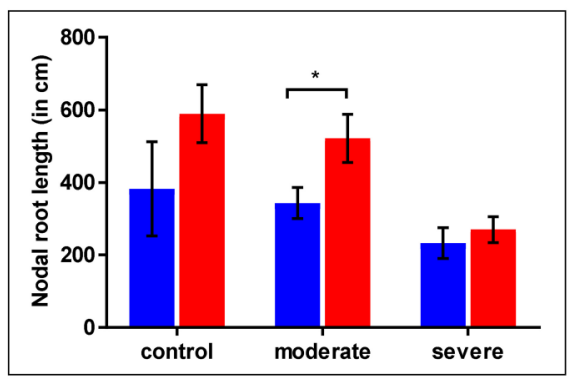

C

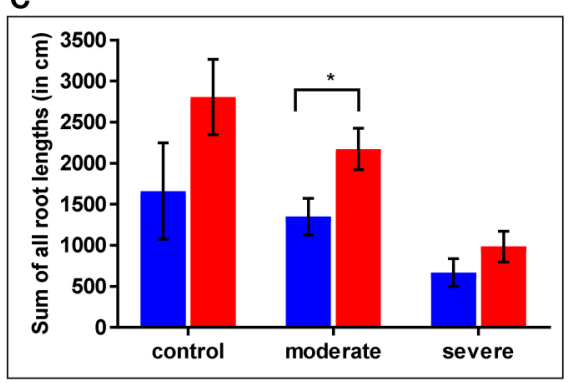

E

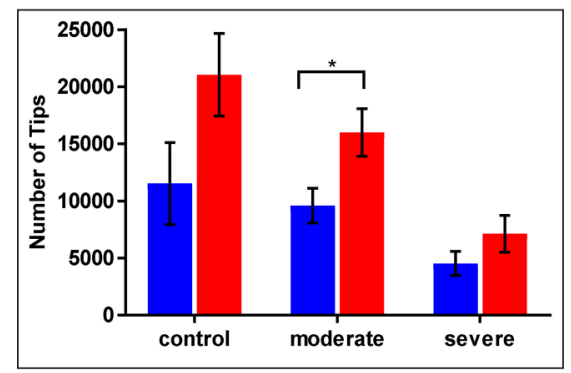

B

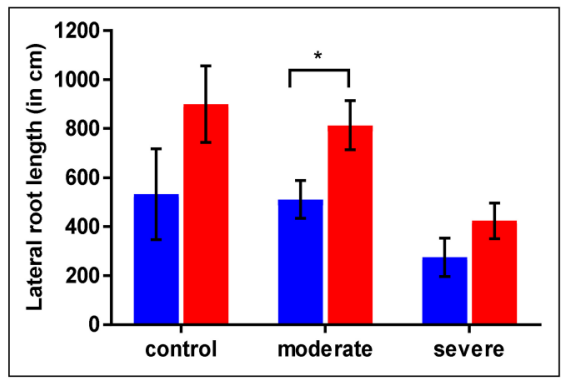

D

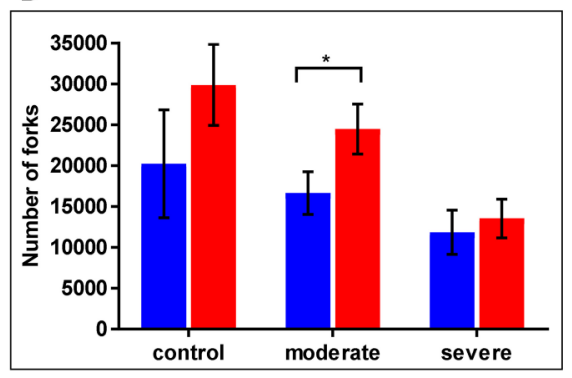

F

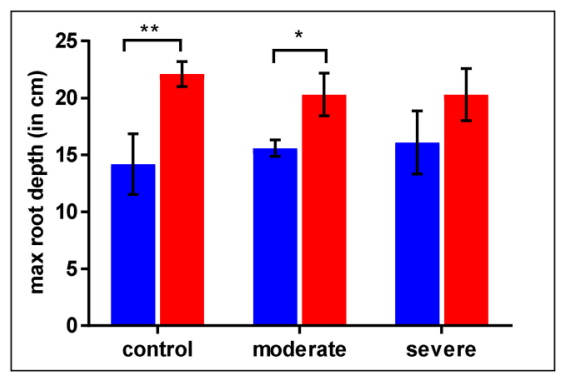

FIGURE 4 | Comparative differences were observed in root architecture in wild type (WT) and cpm2. Plants of two genotypes were grown in soils at different moisture levels. Roots were harvested, washed and stored in $75 \%$ ethanol until scanning and analysis. Significant differences were observed across the treatments. Values for (A) nodal root length (B) lateral root length $\mathbf{( C )}$ sum of all root length (D) number of forks (E) number of tips (F) max root depth are shown here. Data represents mean value \pm standard error (SE); $n=5$. WT and cpm2 are represented by blue and red bars, respectively. Stars $\left(^{*}\right.$ and $\left.{ }^{* *}\right)$ denote statistical significance $(P \leq 0.05$ and $P \leq$ 0.01), respectively, between the two genotypes in a Student's $t$-test.

basis of DAPs that can potentially modify or affect the cell wall structure, composition or properties (Table 1). In cpm2 there was an increased content of six major enzymes of the phenylpropanoid pathway involving cinnamic acid modification, which potentially modify the cell wall composition. The enzymes involved suggest variation in coumaric and ferulic acid content (Figure S5), which was confirmed by the quantification of the coumaric and ferulic acid ester-linked to cell wall biopolymers in the roots. Ester-linked coumaric and ferulic acid contents were both significantly lower in cpm2 compared to the WT under drought (Figures 7A,B). This agreed with the increased content of the enzymes that used the two acids as substrates in cpm2. The levels of ester-linked di-, tri- and total oligo-ferulates were also generally lower in the roots of cpm 2 under drought but significantly so for the measured triferulates (Figure S6C). Under control conditions, there was no significant difference between WT and cpm2 in the content of coumaric or ferulic acid or ferulate oligomers (Figure 7, Figure S6).

\section{DISCUSSION}

\section{Higher WUE and Stomatal Conductance in cpm2 under Drought Stress}

The observation of higher WUE and higher stomatal conductance in cpm2 is somewhat antagonistic. Genotypes bearing higher stomatal conductance may indicate a pronounced capability of uptaking available soil water through enhanced root area (Mitchell et al., 1996) or osmotic adjustment (Blum, 2005), and thereby, can maintain transpiration during moderate drought stress (Blum, 2009). But on the other hand, enhanced stomatal conductance might be a downside when soil water deficits are more common (Donovan et al., 2007). Plants counter severe water deficit by decreasing their stomatal conductance, however by a curtailment of WUE, plants could deplete available water quickly and consequently die by loss of turgor, if they fail in a drought survival strategy (Donovan et al., 2007; Manzoni et al., 2011). In the case of our study, the higher stomatal conductance 


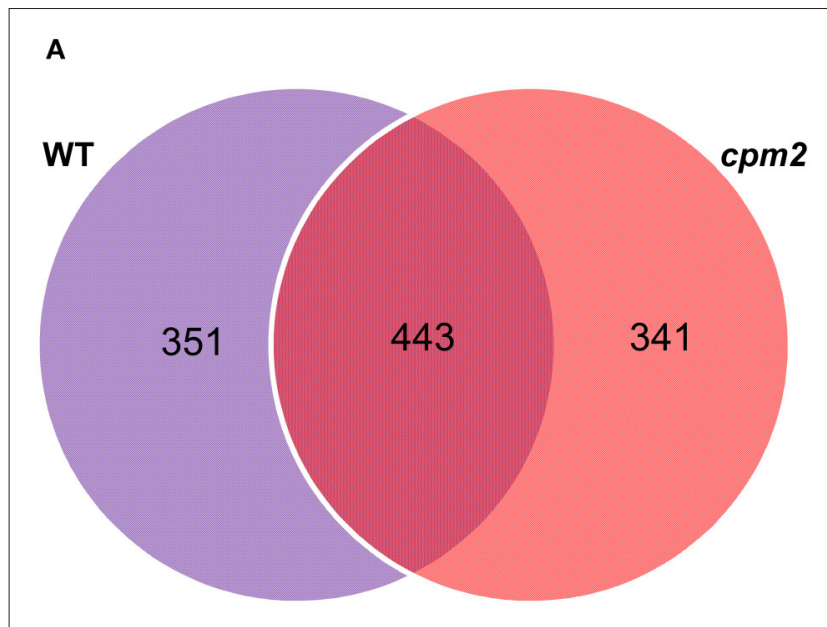

B

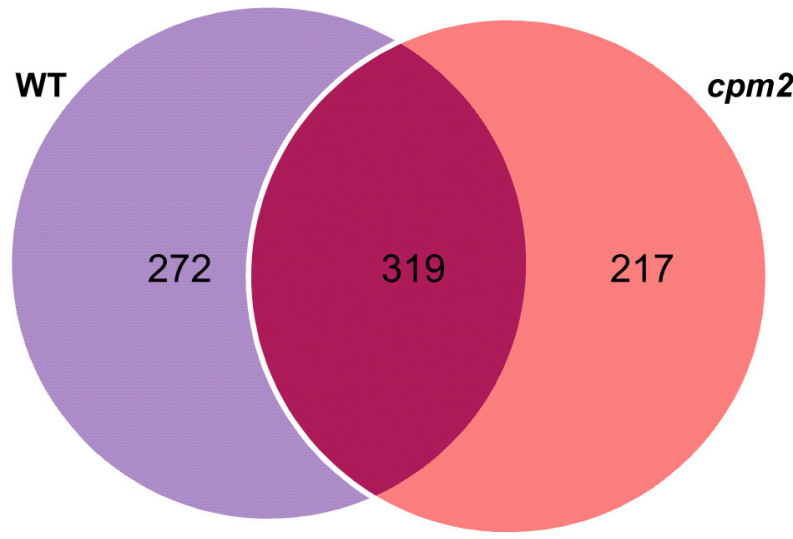

FIGURE 5 | Venn diagrams of proteins obtained after TMT (Tandem Mass Tag) analysis. 4,194 hits were assigned to unique peptides leading to combined identification of a total of 1,578 proteins in wild type $(\mathrm{WT})$ and cpm2 roots. (A) 351 and 341 proteins were uniquely identified in WT and cpm2 roots, respectively, while 443 proteins were common to both. (B) Number of proteins quantified were 272 and 217 unique ones in WT and cpm2, respectively, with 319 common proteins.

may be an effect of greater root length and branching in cpm2. Increase in ABA content under drought is known to be related to stomatal closure in leaves, which increases WUE (Gowing et al., 1990; Zhang and Davies, 1990; Gomes et al., 1997). In fact, the different accumulation of ABA in the shoots of the WT and cpm2 are in agreement with the differences observed in their stomatal conductance (Figures 2, 3A). One could anticipate that due to the high ABA concentration in cpm2 stomatal closure could even be more pronounced as we could observe in our measurements. One explanation for this could be that ABA may need interaction with JA to stimulate stomatal closure (Daszkowska-Golec and Szarejko, 2013). Since cpm2 lacks JA, the stomata may not have been affected to the degree expected despite the increase in $\mathrm{ABA}$. One possibility for a limited effect of $\mathrm{ABA}$ under the lack of JA could be the fact that JA upregulates ABA receptor genes (Lackman et al., 2011), which could thus be limiting in cpm2.
Despite the antagonistic features, cpm2 survived severe drought stress better than the WT. Higher stomatal conductance as well as higher WUE under drought was noted before in some genotypes of peanuts, where root length density was positively correlated to WUE (Songsri et al., 2013). Limiting vegetative growth also increases WUE. The cpm2 plants showed reduced culm development (Figure S2D), which is also supported by lower shoot dry weight under drought in cpm2 (Figure S7). Overall, through the aerial morpho-physiological parameters of leaf rolling, WUE, stomatal conductance, and ABA content as well as the root architecture of increased branching indicated that cpm2 plants had a better potential to tolerate drought.

\section{Root Proteome-Based Insights into Drought Tolerance by cpm2}

A more branched root system as in the case of cpm2 (Figure 4, Figure S3) may provide a significant advantage to counter drought as seen by cross-validating a near isogenic line (NIL) and a transgenic line in field samples of a large-effect QTL for yield under drought (Dixit et al., 2015; Raorane et al., 2015a). During drought stress, the root is the primary organ to sense water scarcity in drying soil, triggering a cascade of responses at morpho-physiological, biochemical, and cellular levels (Sengupta et al., 2011). Hence comparative proteomic studies on roots were undertaken. Adaptive growth of the $c p m 2$ roots under drought was evidently supported through various DAP categories.

\section{DAPs in ROS Scavenging Enzymes Are More Abundant in cpm2}

Two glutathione-S-transferases (GST; OsGSTF2, and OsGSTU12) were more abundant in cpm2 (Figure 8). GSTs are well known for their role in detoxification of xenobiotics, they also work as antioxidants by tagging and removal of oxidative degradation products, especially from fatty acids and nucleic acids (Moons, 2005). GSTs may also act as glutathione peroxidase to directly scavenge peroxides (Frova, 2003). Also, ascorbate peroxidase (APX) participates in ascorbate-glutathione cycle, and hence is functional in free radical detoxification (Cramer et al., 2013). In cpm2, the OsAPX7 was also more abundant (Figure 8). Both glutathione (GSH) and ascorbate (AsA) are also important non-enzymatic antioxidants for plant defense against oxidative stress (Foyer and Noctor, 2005). In cpm2, some other proteins with antioxidant activities were also more abundant. Under various abiotic and biotic conditions in plants, serine hydroxymethyltransferases reportedly participate in dissipative mechanisms to curtail the production of ROS (Moreno et al., 2005). Their antioxidant activity may also be related to the serine-glycine-glutathione synthesis pathway. One serine hydroxymethyltransferase, OsSHMT2, was more abundant in cpm2 (Figure 8). Similarly, a DJ-1 family protein was also more abundant in cpm2 (Figure 8). They are known to possess antioxidant property reportedly through detoxifying glyoxal/methyl-glyoxal (Ghosh et al., 2016), and accelerated cell-death is also reported due to their loss of function (Xu et al., 2010). A 3-isopropylmalate dehydrogenase (3-IPMD) was also more abundant in cpm2 (Figure 8). This enzyme is involved in leucine and glucosinolate biosynthesis 


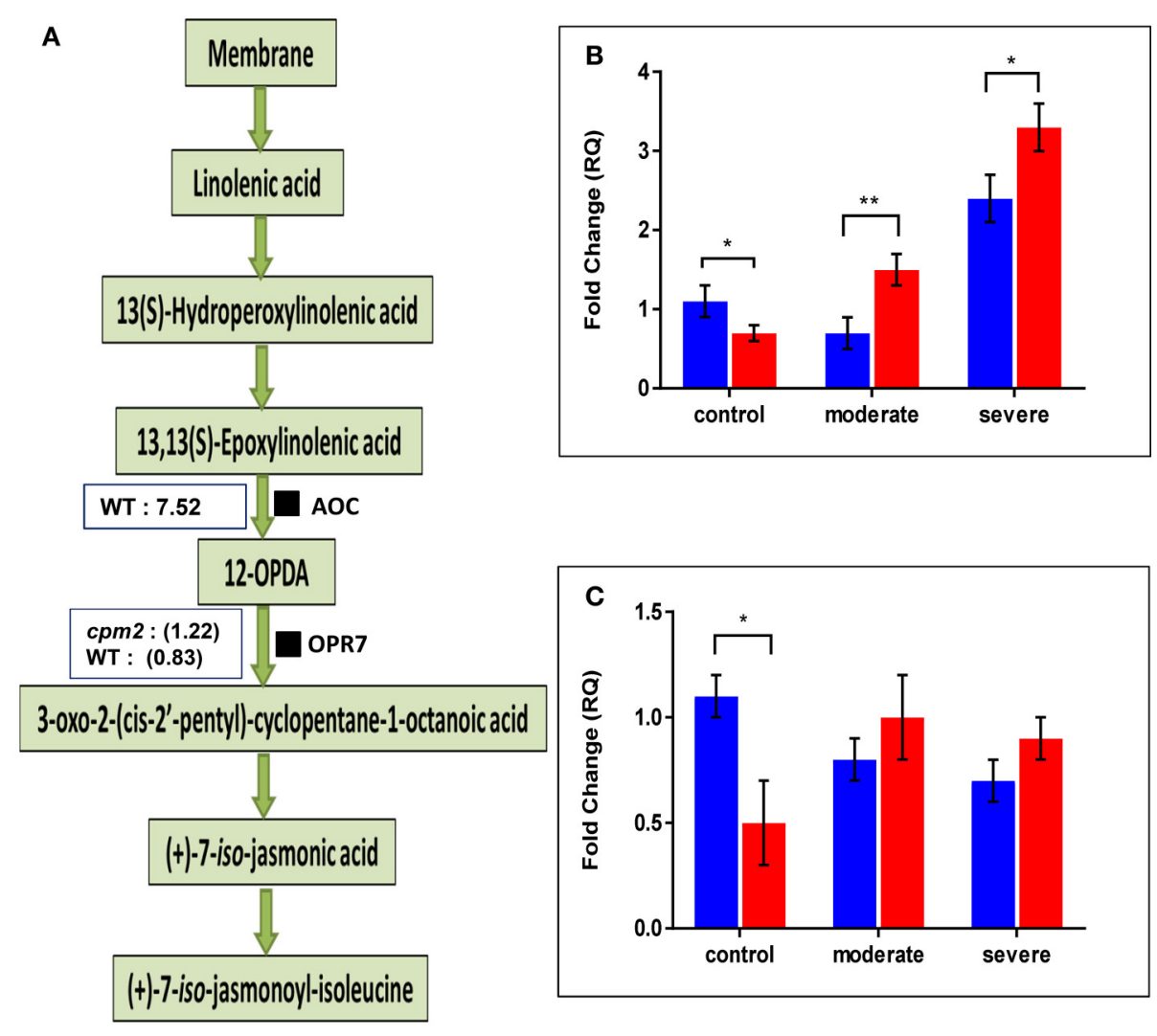

FIGURE 6 | Effect of drought on enzymes involved in JA biosynthesis and their transcript levels. (A) Overview of the jasmonic acid pathway with log ratios (stress/control) for AOC and OPR7protein are shown in boxes, respectively. Transcript abundances of mRNAs encoding (B) AOC and (C) OPR7protein were analyzed at control, moderate and severe drought stress conditions. Wild type (WT) and cpm2 are represented by blue and red bars, respectively. Data represents mean value \pm standard error (SE); $n=3$. Stars ( ${ }^{*}$ and $\left.{ }^{\star *}\right)$, denote statistical significance $(P \leq 0.01$ and $P \leq 0.001)$, respectively, between the two genotypes in a Student's $t$-test.

(He et al., 2009). Glucosinolates act by inducing antioxidative enzymes such as GSTs (Vig et al., 2009). The 3-IPMD was classified as an antioxidant upregulated by JA (Sasaki-Sekimoto et al., 2005). Yet it is present in larger amount in $c p m 2$ which lacks JA. Amongst the redox category, non-symbiotic hemoglobin2 (nSHb2) was the only protein reported to be less abundant in cpm2 (Figure 8). Limited information is available about this class of protein or its probable function under abiotic stress, but it is known to be upregulated under hypoxia in plant roots (Riquelme and Hinrichsen, 2015). A positive correlation was established between $\mathrm{nSHb} 2$ and the amount of $\omega-3 \alpha$-linolenic acid, a precursor of JA, in the Arabidopsis seeds (Vigeolas et al., 2011). It cannot be said at this stage if the lack of JA in cpm 2 was a reason for reduced levels of nSHb2 under drought.

\section{DAPs in Energy-Generating Carbon/Nitrogen Catabolism Indicates Higher Resource Mobilization in cpm2}

Glycolysis is a major metabolic pathway participating in carbohydrate metabolism, and drought stress triggers altered amino acid and sugar contents (Raorane et al., 2015b,a). In cpm2, three DAPs related to carbon catabolism were more abundant; triose phosphate isomerase (TPI), glyceraldehyde 3phosphate dehydrogenase (G3PD) and pyruvate decarboxylase
(PDC) (Figure 8). G3PD may serve as a direct link relating energy metabolism, membrane lipid-based signaling and control of a plant's growth in response to ROS and water stress (Guo et al., 2012). TPI is reported to participate in plant stress response and under drought stress, its expression is also induced in maize (Riccardi et al., 1998). Being the first and key participating enzyme during ethanolic fermentation, pyruvate decarboxylase (PDC) splits the main glycolytic pathway at pyruvate (Zabalza et al., 2009). Ethanolic fermentation is reported to occur not only under anaerobic conditions but also under stress conditions (Chen and Han, 2011). Similarly, some protein catabolism-related enzymes specific to proteasomes, such as, the threonine proteases T1-family peptidases, were more abundant in cpm2 (Figure 8). Increased proteasome activity under stress is related to degradation of oxidized proteins, thus contributing to tolerance of oxidative stress (Kurepa et al., 2009). Protein degradation feeds into a favorable nitrogen status of the roots under drought (Kohli et al., 2012). A favorable nitrogen status of cpm2 under drought was also supported by more abundance of Glutamine Synthetase (Figure 8). Serving as the first enzyme in the nitrogen assimilatory pathway, GS is known to regulate nitrogen metabolism and plant productivity (Lea and Miflin, 2011) and has been shown to be upregulated at the transcript and protein level under drought in rice (Raorane 
TABLE 1 | List of Differentially abundant Proteins (DAPs) showing highest abundance in WT and cpm2 under drought stress.

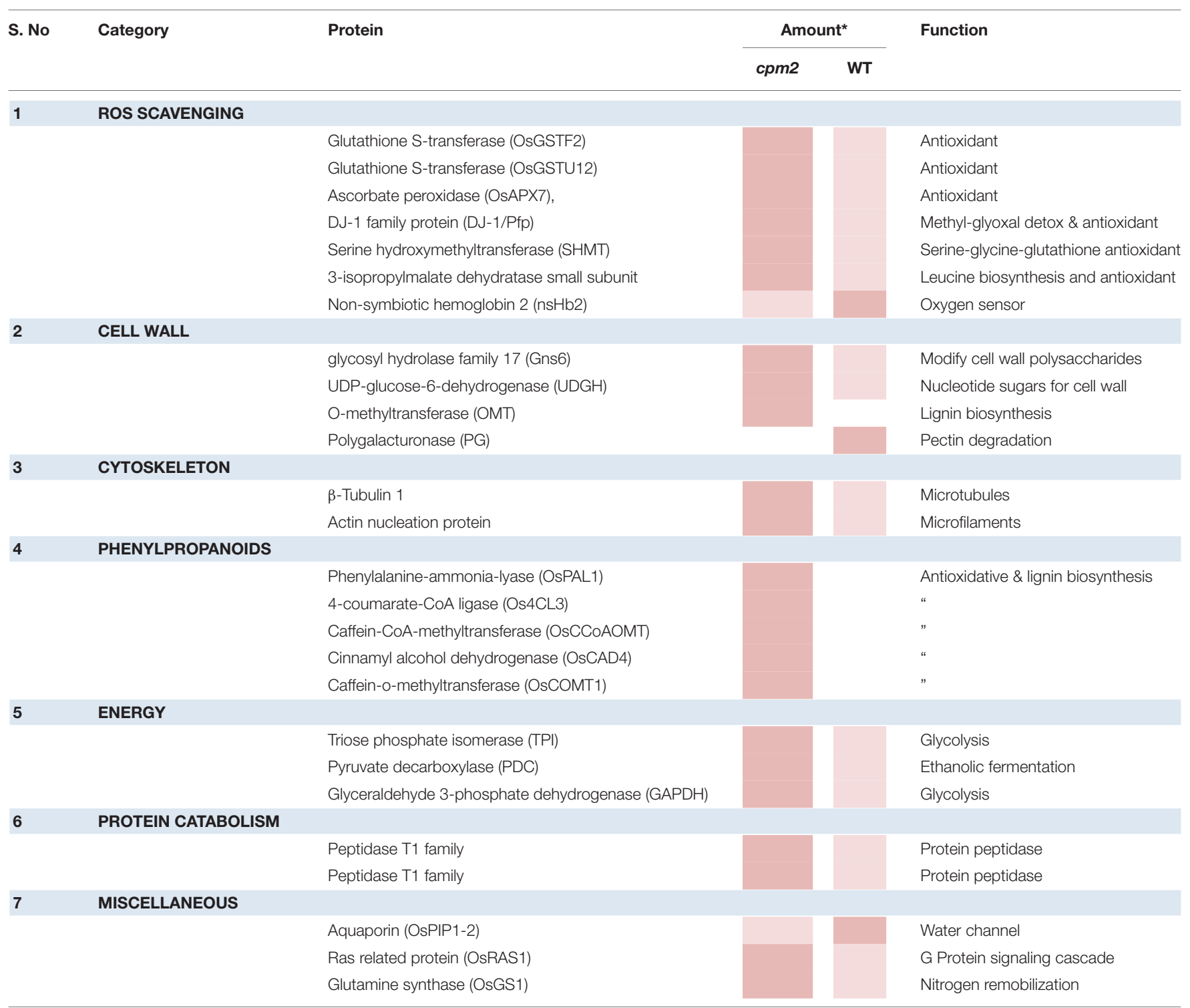

*Abundance of protein is shown by contrasting shades. White color in column refers to absence of protein. See Figure 8 for details

et al., 2015b,a). It is also reported that increased expression of GS enhances drought and salinity tolerance (Kalamaki et al., 2009).

\section{DAPs-Mediated Changes in Root Cell Walls Suggests More Active Root Development in cpm2}

Roots quickly respond to changes in water potential and significantly alter morpho-physiological traits (Henry et al., 2012; Sandhu et al., 2016). Several DAPs such as a glycoside hydrolase (GH; family 17), O-methyl transferase (OMT), UDP-D-Glucose dehydrogenase, tubulin, and actin nucleation protein (Figure 8) suggested the ability of $c p m 2$ roots to stimulate cell wall adaptations during drought. GH17 endohydrolases cleave 1,3-Dglucosidic linkages linking $\beta$-1,3-glucans and therefore affect cellwall assembly and rearrangement. GH17 endohydrolase activity has been linked with improved performance of rice plants under stress conditions such as, mechanical wounding or fungal stress (Jwa et al., 2006). The GH17 endohydrolase as a DAP was more abundant in cpm2 (Figure 8). Similarly, an OMT was more abundant in cpm2 (Figure 8). It is evident that OMTs may participate in several biotic and abiotic stress responses (Barakat et al., 2011). Being multifunctional enzymes, OMTs are reportedly known to play diverse role in various processes such as cell wall adaptation and catalyzing $O$-methylation of multiple secondary metabolites that are known participants during metabolic processes like plant growth, development, and environmental cues (Kim et al., 2010; Urbanowicz et al., 2012). A UDP-D-glucose dehydrogenase (UDPGDH) was also present in larger amount in cpm2 (Figure 8). UDPGDH oxidizes UDP-D-glucose (UDP-Glc) to UDP-D-glucuronate (UDP-GlcA) the known precursor of UDP-xylose and UDP-arabinose, the precursors of arabinoxylans, the major hemicellulosic 

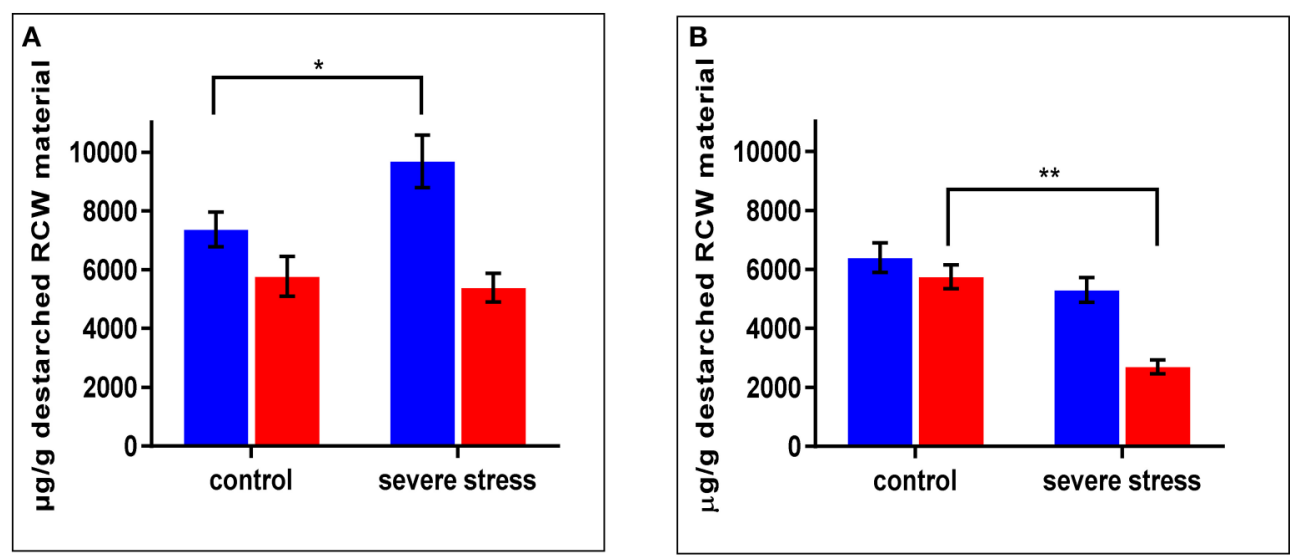

FIGURE 7 | Ester linked (A) Coumaric Acid) (B) Ferulic Acid levels in wild type (WT) and cpm2 destarched root cell wall (RCW) material under control and severed rought stress conditions. Both the metabolites in the cell wall-bound state were less in roots exposed to drought in cpm2. Three-week-old WT and cpm2 seedlings were either kept well-watered, and their roots were sampled at day 22, or watering was stopped to initiate severe stress condition. Root samples were harvested in control and severe stress condition. WT and cpm2 are represented by blue and red bars, respectively. Data represents mean value \pm standard error (SE); $n=5$. Stars ${ }^{*}$ and $\left.{ }^{* *}\right)$ denote statistical significance $(P \leq 0.05$ and $P \leq 0.01)$, respectively, between the two genotypes in a Student's $t$-test.

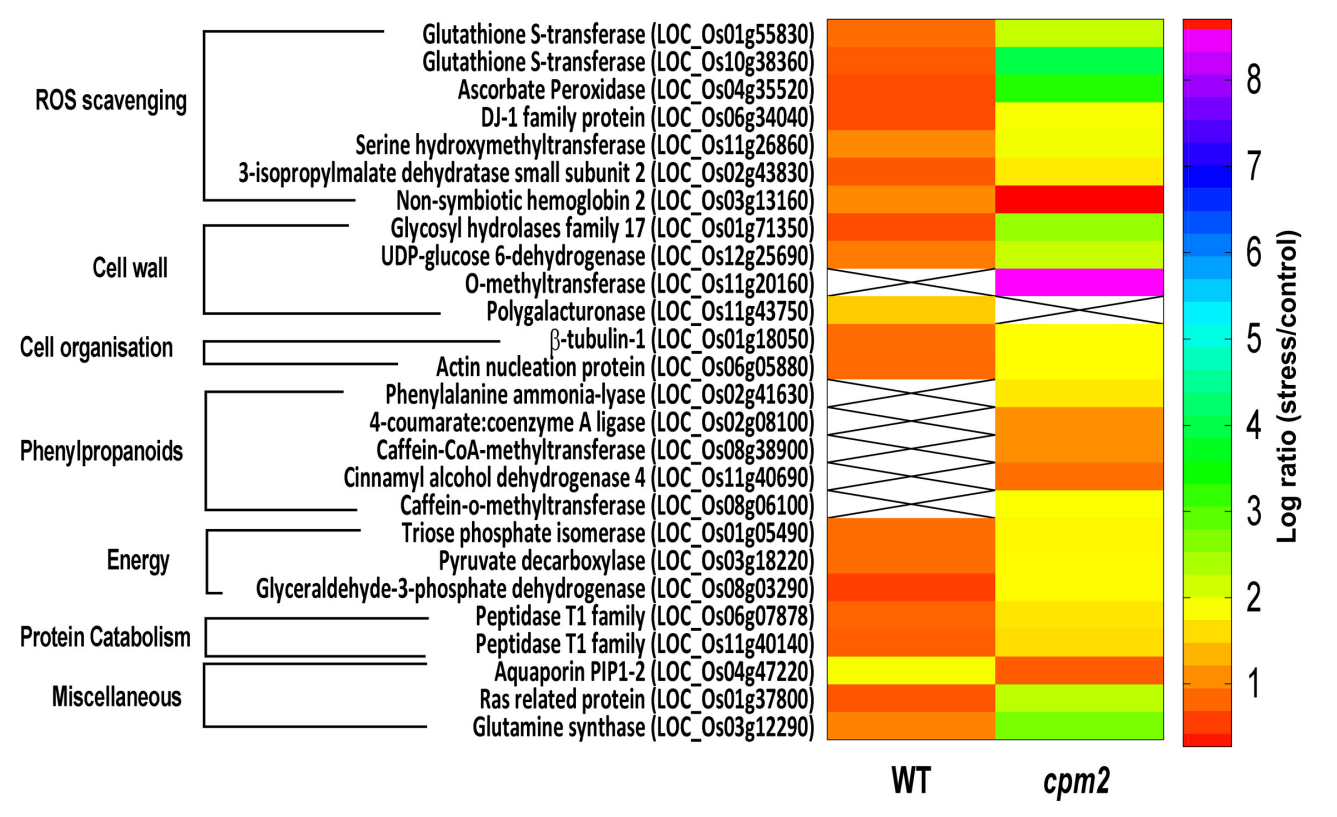

FIGURE 8 | Heat map of differentially abundant proteins (DAPs) belonging to ROS scavenging, cell wall, cell organization, phenylpropanoids, energy, proteincatabolism and miscellaneous categories obtained after TMT (Tandem Mass Tag) analysis of cpm2 and wild type (WT) roots. Differential proteins were abundant in cpm2 (except nSHB2 and PIP-2) as evident from the log ratios (stress/control). TMT based LC-MS/MS analysis was performed on rice roots after drought treatment of cpm2 and corresponding WT. Total protein was extracted and subsequent FASP digestion was performed. The subsequent peptide mixture was labeled with the TMT reagent prior to multiplexing. Pooled peptides were fractioned using the reversed-phase HPLC system and then individual fractions were analyzed using Tandem mass spectrometry. For each protein the ID according to MSU is provided in parenthesis. The color scale indicates whether a protein is more or less abundant under drought conditions. Cross marks indicate that the protein was unidentified in the respective sample.

polysaccharide in the graminaceous cell wall (Kärkönen, 2005). More UGPGDH in cpm2 suggests increased biosynthesis of hemicelluloses and cell wall remodeling in response to stress (Kärkönen et al., 2005). Yoshimura et al. (2008) also reported accumulation of UDPGDH in watermelon roots during drought stress.
Adaptive growth of cpm2 roots under drought relates well to higher amounts of enzymes engaged in the formation of cell walls. Microtubules are an essential component of the cell's cytoskeleton, and tubulins are a crucial component of these microtubules that are functional during numerous cellular processes, ranging from cell division to intracellular 
transport inside eukaryotic organisms (Zhao et al., 2014) and determination of the orientation of cellulose fibrils in the cell wall (Schmit and Nick, 2008). $\beta$-Tubulin-1 was reported as more abundant in cpm2 (Figure 8). Likewise, an actin nucleation protein, which acts in cell elongation, cell shape maintenance, and polarized growth of root hair (Ramachandran et al., 2000) was also more abundant in cpm2 (Figure 8). Upregulation of the microtubule components under drought in rice roots has been reported earlier (Raorane et al., 2015b,a).

\section{DAPs in Phenylpropanoid Pathway Increased Cell Wall Modification in cpm2}

Water deficiency modulates the expression of lignin biosynthesis genes (Santos et al., 2015). Of the nine identified DAPs related to cell wall biosynthesis and remodeling, six encompass lignin biosynthesis and five of these belong to the phenylpropanoid biosynthetic pathway (Table 1). Such DAPs more abundant in cpm2 were OsPAL1, Os4CL3, OsCAD4, OsCOMT1, and OsCCoAOMT (Figure 8, Figure S5), and these are crucial for lignin biosynthesis in rice plants (Gui et al., 2011; Hirano et al., 2012; Koshiba et al., 2013; Yoon et al., 2015; Wang et al., 2017). Transcript analysis of these genes revealed some interesting trends. OsPAL1 increased in both genotypes under moderate stress, but under severe stress it was similar in wild type and cpm2 (Figure S8A). The Os4CL3 transcript was more abundant in cpm2 under moderate and severe drought (Figure S8B) while the OsCOMT1 transcript was similarly upregulated in cpm 2 under moderate stress but was not significantly different under severe stress (Figure S8C). Taken together, the transcript and protein abundance data in the phenylpropanoid pathway suggested an increase in the biosynthesis of phenolics and/or lignin (Vincent et al., 2005; Fan et al., 2006; Phimchan et al., 2014) in cpm2.

Since coumarates are also known to be incorporated into the lignin structure, increased lignin in $c p m 2$ suggested increased coumarates. The level of esterified $p$-coumarates was higher under drought in the WT but not in cpm2 (Figure 7A). Phloroglucinol staining for lignifications also showed increase in lignin in the WT root section but not in cpm2 (Figure S9). To resolve the discrepancy in cpm2 between the potentially increased biosynthesis of phenolics/lignin but relatively lesser lignin content visualized through phloroglucinol, quantitative estimation of the changes in the lignin polymer composition (monolignol ratios and linkage types within the polymer) will be conducted in future, because phloroglucinol best stains cinnamaldehydes (Adler, 1977) while the extent of lignin crosslinking can affect visualization by phloroglucinol (Pomar et al., 2002). The increase of the elastic modulus but reduced plastic extensibility of the cell wall under drought (Blum, 2011) is caused in part by augmented cross-linking of arabinoxylans to each other and lignin via free-radical-induced oxidative coupling of phenolics like lignin monomers and ferulates (Fan and Neumann, 2004; Fan et al., 2006).

$p$-Coumaric acid is also found ester-linked to arabinoxylans just like ferulic acid (Mueller-Harvey et al., 1986). No significant difference in the arabinose/xylose ratio was found in the cpm2 roots' cell wall material under drought in contrast to WT, which had a lower arabinose/xylose ratio in the drought-stressed roots compared to the control (Figure S10). The arabinose/xylose ratio is an indicator of the degree of substitution of the arabinoxylan polymer backbone, which has been shown to be reduced in drought-stressed plants (Rakszegi et al., 2014). Contrary to our expectations based on the protein biosynthesis data, droughtstressed cpm2 roots showed reduced biosynthesis of both esterlinked ferulic acid monomers (Figure 7B) and the oligoferulates (dimers and trimers) involved in cell-wall crosslinking compared to the control (Figure S6). Drought stress also resulted in fewer diferulates in the WT roots compared to the control (Figure $\mathrm{S} 6 \mathrm{~B})$. Both osmotic stress and ABA have been previously shown to reduce ester-linked ferulate and diferulate content in wheat coleoptiles (Wakabayashi et al., 1997a,b). The results indicate that rice roots respond to drought stress by loosening cross-links in the cell wall, to become more flexible. However, JA might inhibit this response, as WT roots show a weaker decrease in those crosslinking metabolites under drought stress.

Discrepancies in the results expected for the cpm2 cell walls from more abundant DAPs for phenylpropanoid and ferulate pathways could potentially be ascribed to alternate uses of the secondary metabolite products of the enzymes involved. For example, the phenylpropanoid pathway involving chorismate and shikimate could be directed to salicylic acid (SA) synthesis, which like JA is perhaps equally but antagonistically involved in drought response (Pedranzani and Vigliocco, 2017).

\section{Lower Abundance of DAPs for Aquaporins in cpm2 Could Influence Root Water Status Positively}

Plasma membrane intrinsic proteins (PIP), a subfamily of aquaporins comprising two subgroups of PIP1 and PIP2 could also influence root water status. PIP2 proteins could be attributed for enhanced water channel activity (Chaumont et al., 2000). In the present study, OsPIP1 was less abundant in cpm2 (Figure 8). Reduced expression of some of the PIP genes could lead to inhibition of water loss by preventing backflow of water to dried soil (Afzal et al., 2016). Moreover, down-regulation of PIP genes transcription was also reported in the roots of tobacco (Mahdieh et al., 2008) and also in the twigs and roots of olive plants (Secchi et al., 2007).

\section{Impaired AOC Function Useful for Drought Tolerance}

Drought stress apparently upregulates the JA biosynthetic pathway as evident at the transcript and protein level in our study and in earlier reports in rice (Du et al., 2013). In the root proteome analysis $\mathrm{AOC}$ was unique and highly abundant under drought in the WT (Figure 6A). Moreover, we also found 12-OXOPHYTODIENOATE REDUCTASE (OPR7), another protein downstream of AOC in the JA biosynthesis pathway, was more abundant under drought in cpm2 roots (Figure 6A). However, when comparing OPDA, JA, and JA-Ile levels between WT and cpm 2 shoots and roots under control, moderate and severe stress, minor differences were found, except in the OPDA levels in WT shoots during severe stress (Figures S11A-F). Even though the amounts detected for these hormones under our specific experimental conditions were rather low. 
These results raise two important questions. First, how can upregulation of JA synthesis genes under drought be reconciled with its proposed role as a negative regulator of drought tolerance?, the latter ascertained from morpho-physiological responses and root proteome indicators in cpm2 that lacks JA. Possibly, increase in JA content under drought upregulates some JA responsive genes (JRG) that are negative regulators of drought tolerance. Hence lack of JA in cpm2 does not upregulate the negative regulators of drought tolerance. For example, one of the JRGs, chlorophyllase 1 (CLH1) is a senescence associated gene (Sasaki et al., 2001) the upregulation of which may not be useful. JA induced natural senescence in maize has been reported (Yan et al., 2012). Additionally, the complex crosstalk of JA with other plant hormones such as ABA, salicylic acid (SA) and ethylene may dictate its final effect. For example, another JRG highlighted by Sasaki et al. (2001) is a SA-glucosyltransferase, which can inhibit SA signaling while SA is known to be important in abiotic stress tolerance (Pedranzani and Vigliocco, 2017). Also, recently Liu and Avramova (2016) reported that JA was not able to induce any of the dehydration response genes tested but it potentiated ABA-dependent genes. Thus JA crosstalk to other hormones may underpin the drought response rather than a direct relationship between its upregulation and action. Second, under the lack of AOC protein and hence the suspected lack of 12-OPDA, the substrate for OPR7, how OPR7 can be upregulated? Potentially the transcription and translation of downstream OPR7 gene was not dependent on the product of AOC activity (12-OPDA). Similar to our results in Figure S11, detectable amounts of OPDA and JA remained in the maize single mutants for OPR7 as observed by Yan et al. (2012) who speculated other members of the OPR gene family to be responsible for low but measurable amounts of JA in the opr7 mutant. However, similar results of detectable OPDA and JA synthesis in the mutants of two different genes for JA synthesis, in two different crops, present an intriguing scenario and suggest unexplored cryptic regulation of JA biosynthesis. It must be noted that OPDA and JA content in the WT roots under drought was as low as that of the cpm2 (Figures S11D,E). This suggested that the comparatively decreased contents of OPDA and JA in cpm2 under the control conditions had some effect rather than the drought-mediated decrease per se. Finally, since hormone levels are transient it is possible to have missed the critical time points during which alterations could be detected. Nevertheless, from the proteomic evidence, it can be speculated that in the WT roots, owing to the abundance of AOC but scarcity of the downstream OPR7, OPDA is accumulated. This speculation is also in agreement with the findings of Savchenko et al. (2014). Moreover using cpm2 and corresponding WT for a study on salinity stress, Hazman et al. (2015) reported that an increase in OPDA content in WT was perceived as a damage signal. We observed similar increase in the OPDA amounts at least in the shoots of the WT during severe stress condition (Figure S11A), but in order to further validate this finding at the metabolite level in drought stressed roots, further quantification of jasmonates must be conducted at the more precise and early time point after onset of stress.

\section{Conclusions and the Proposed Role of JA in Response to Drought}

In cpm2, the response to drought stress at the initiation of water deficit condition was much faster than in the WT, as also evident from its lower stomatal conductance. Overall, the mutant displayed a better fitness to combat drought stress conditions through effective activation of stress-preventing mechanisms that further led to its better sustenance under drought.

In summary, in comparison to the WT, cpm 2 exhibited:

(1) morpho-physiological adaptations to drought through lower stomatal conductance (at the onset of stress), higher ABA levels and higher WUE.

(2) Better root system under control and drought conditions as revealed by WinRHIZO based measurements.

(3) Comparative root proteome analysis supported a better status of $c p m 2$ roots in terms of more efficient ROS scavenging, more abundance of cell wall-modifying, energygenerating, and water-saving enzymes/proteins.

(4) Transcript and protein abundance data in the phenylpropanoid pathway suggested an increase in the biosynthesis of phenolics and/or lignin in cpm2. Moreover, cell wall metabolite analysis revealed a unique profile for $c p m 2$ under drought stress. However, in the future quantitative measurements of the lignin polymer composition (monolignol ratios and linkage types within the polymer) will be necessary to further validate these observations.

(5) In the WT shoots, OPDA levels were found to be higher under severe drought. Similarly, in the WT roots, based on proteomic results OPDA is speculated to be accumulated due to high abundance of AOC and scarcity of OPR7. These observations are in agreement with the previous findings of Savchenko et al. (2014) and Hazman et al. (2015), however this finding for drought also needs to be further validated at metabolite level in the roots wherein, more early timepoint samples need to be collected after the start of stress treatment-to further detect immediate and direct changes in these hormones. Additionally, potential hormone crosstalk was implicated through our study, which warrants further research, namely that ABA may need JA for stomatal closure and that JA effects may be modulated through the involvement of SA.

All of the aforesaid attributes allowed $c p m 2$ to optimize its growth in response to a water deficit condition and to further withstand a prolonged drought stress. Presently, it is not possible to define the exact mechanisms controlling better drought responses in cpm2. However, based on the integration of root proteome, metabolite and morpho-physiological data, we can rather propose the key molecular players involved in the better sustenance of cpm2 during drought. We believe that the results presented in this study are a key in further advancements toward understanding the precise role of JA during drought stress tolerance and also the molecular mechanisms involved. Thus, we conclude that drought response of cpm2 implicated JA as a negative regulator of root growth and overall drought tolerance. 


\section{AUTHOR CONTRIBUTIONS}

$\mathrm{RD}$ performed the morpho-physiological characterization experiments, generated all plant sampling material, prepared RNA and protein samples, performed TMT labeling experiments, analyzed and interpreted the morpho-physiological, cell wall metabolite and root proteome results, and wrote the manuscript; MLR helped in sampling plant materials, performed transcript analysis of $A O C$ and $O P R 7$, interpreted the proteome and metabolite data and participated in writing the manuscript. AT performed the LC-MS/MS and bioinformatics analysis for the root proteomics data. PP performed the qRT-PCR analysis of genes related to phenylpropanoid pathway. RS and MB performed the cell wall metabolite analysis and its interpretation, respectively. VS performed the root histological studies. $\mathrm{BH}$ performed the plant hormone measurements and participated in manuscript writing. AH designed and supervised the physiological experiments and participated in interpreting the morpho-physiological data. AK and MR together conceptualized and supervised the whole study as well as participated in writing the manuscript.

\section{REFERENCES}

Adler, E. (1977). Lignin chemistry-past, present and future. Wood Sci. Technol. 11, 169-218. doi: 10.1007/BF00365615

Afzal, Z., Howton, T., Sun, Y., and Mukhtar, M. S. (2016). The roles of aquaporins in plant stress responses. J. Dev. Biol. 4:9. doi: 10.3390/jdb4010009

Balbi, V., and Devoto, A. (2008). Jasmonate signalling network in Arabidopsis thaliana: crucial regulatory nodes and new physiological scenarios. New Phytol. 177, 301-318. doi: 10.1111/j.1469-8137.2007.02292.x

Balcke, G. U., Handrick, V., Bergau, N., Fichtner, M., Henning, A., Stellmach, H., et al. (2012). An UPLC-MS/MS method for highly sensitive highthroughput analysis of phytohormones in plant tissues. Plant Methods 8:47. doi: 10.1186/1746-4811-8-47

Barakat, A., Choi, A., Yassin, N. B. M., Park, J. S., Sun, Z., and Carlson, J. E. (2011). Comparative genomics and evolutionary analyses of the O-methyltransferase gene family in Populus. Gene 479, 37-46. doi: 10.1016/j.gene.2011.02.008

Blum, A. (2005). Drought resistance, water-use efficiency, and yield potential are they compatible, dissonant, or mutually exclusive? Austr. J. Agric. Res. 56, 1159-1168. doi: 10.1071/AR05069

Blum, A. (2009). Effective use of water (EUW) and not water-use efficiency (WUE) is the target of crop yield improvement under drought stress. Field Crops Res. 112, 119-123. doi: 10.1016/j.fcr.2009.03.009

Blum, A. (ed.). (2011). "Phenotyping and selection," in Plant Breeding for WaterLimited Environments (New York, NY: Springer), 153-216.

Bouman, B. A. M., Humphreys, E., Tuong, T. P., and Barker, R. (2007). Rice and water. Adv. Agron. 92, 187-237. doi: 10.1016/S0065-2113(04)92004-4

Chaumont, F., Barrieu, F., Jung, R., and Chrispeels, M. J. (2000). Plasma membrane intrinsic proteins from maize cluster in two sequence subgroups with differential aquaporin activity. Plant Physiol. 122, 1025-1034. doi: $10.1104 /$ pp.122.4.1025

Chen, B., and Han, B. (2011). Primary function analysis of a pyruvate decarboxylase gene, OsPDC3, in rice. Chin. J. Rice Sci. 25, 567-574. doi: 10.3969/j.issn.1001

Cramer, G. R., Van Sluyter, S. C., Hopper, D. W., Pascovici, D., Keighley, T., and Haynes, P. A. (2013). Proteomic analysis indicates massive changes in metabolism prior to the inhibition of growth and photosynthesis of grapevine (Vitis vinifera L.) in response to water deficit. BMC Plant Biol. 13:49. doi: 10.1186/1471-2229-13-49

Daszkowska-Golec, A. (2016). "The role of abscisic acid in drought stress: how ABA helps plants to cope with drought stress," in Drought Stress Tolerance

\section{ACKNOWLEDGMENTS}

This work was supported by a Ph.D. fellowship from Indian Council of Agricultural Research (ICAR-IF) to RD and PP. RD, PP, and MR also acknowledge the travel grants provided by Karlsruhe House of Young Scientists (KHYS) for the field trips to IRRI. We also thank Dr. R. K. Singh (IRRI) for facilitating mutant seed import at IRRI and for providing technical support for their multiplication. We acknowledge the support by Deutsche Forschungsgemeinschaft and Open Access Publishing Fund of Karlsruhe Institute of Technology. This work has been supported by funds to RD by the German Federal Ministry for Research and Education and Egyptian Science and Technology Development Fund (01DH14013).

\section{SUPPLEMENTARY MATERIAL}

The Supplementary Material for this article can be found online at: https://www.frontiersin.org/articles/10.3389/fpls.2017. 01903/full\#supplementary-material

in Plants, Vol. 2 Molecular and Genetic Perspectives, eds M. A. Hossain, S. H. Wani, S. Bhattacharjee, D. J. Burritt, and L.-S. P. Tran (Cham: Springer International Publishing), 123-151.

Daszkowska-Golec, A., and Szarejko, I. (2013). Open or close the gate-stomata action under the control of phytohormones in drought stress conditions. Front. Plant Sci. 4:138. doi: 10.3389/fpls.2013.00138

Dhakarey, R., Kodackattumannil Peethambaran, P., and Riemann, M. (2016). Functional analysis of jasmonates in rice through mutant approaches. Plants 5:E15. doi: 10.3390/plants5010015

Dixit, S., Singh, A., and Kumar A. (2014). Rice breeding for high grain yield under drought: a strategic solution to a complex problem. Int. J. Agron. 2014:863683. doi: 10.1155/2014/863683

Dixit, S., Kumar Biswal, A., Min, A., Henry, A., Oane, R. H., Raorane, M. L., et al. (2015). Action of multiple intra-QTL genes concerted around a colocalized transcription factor underpins a large effect QTL. Sci. Rep. 5:15183. doi: 10.1038/srep15183

Donovan, L. A., Dudley, S. A., Rosenthal, D. M., and Ludwig, F. (2007). Phenotypic selection on leaf water use efficiency and related ecophysiological traits for natural populations of desert sunflowers. Oecologia 152, 13-25. doi: 10.1007/s00442-006-0627-5

Du, H., Liu, H., and Xiong, L. (2013). Endogenous auxin and jasmonic acid levels are differentially modulated by abiotic stresses in rice. Front. Plant Sci. 4:397. doi: 10.3389/fpls.2013.00397

Fan, L., and Neumann, P. M. (2004). The spatially variable inhibition by water deficit of maize root growth correlates with altered profiles of proton flux and cell wall pH. Plant Physiol. 135, 2291-2300. doi: 10.1104/pp.104.041426

Fan, L., Linker, R., Gepstein, S., Tanimoto, E., Yamamoto, R., and Neumann, P. M. (2006). Progressive inhibition by water deficit of cell wall extensibility and growth along the elongation zone of maize roots is related to increased lignin metabolism and progressive stelar accumulation of wall phenolics. Plant Physiol. 140, 603-612. doi: 10.1104/pp.105.073130

FAO (2016). FAO Rice Market Monitor. Vol. 19.

Foyer, C. H., and Noctor, G. (2005). Redox homeostasis and antioxidant signaling: a metabolic interface between stress perception and physiological responses. Plant Cell 17, 1866-1875. doi: 10.1105/tpc.105.033589

Frova, C. (2003). The plant glutathione transferase gene family: genomic structure, functions, expression and evolution. Physiol. Plant. 119, 469-479. doi: 10.1046/j.1399-3054.2003.00183.x

Ghosh, A., Kushwaha, H. R., Hasan, M. R., Pareek, A., Sopory, S. K., and SinglaPareek, S. L. (2016). Presence of unique glyoxalase III proteins in plants 
indicates the existence of shorter route for methylglyoxal detoxification. Sci. Rep. 6:18358. doi: 10.1038/srep18358

Gomes, M. D. M., Lagôa, A., Machado, E., and Furlani, P. (1997). Gas exchange and abscisic acid quantification in two upland rice cultivars submitted to water deficiency. Braz. J. Plant Physiol. 9, 177-183.

Gowing, D. J. G., Davies, W. J., and Jones, H. G. (1990). A positive root-sourced signal as an indicator of soil drying in apple, Malus x domestica Borkh. J. Exp. Bot. 41, 1535-1540. doi: 10.1093/jxb/41.12.1535

GRiSP (Global Rice Science Partnership). (2013). Rice Almanac, 4th Edn. Los Baños, Philippines: International Rice Research Institute. 283.

Gui, J., Shen, J., and Li, L. (2011). Functional characterization of evolutionarily divergent 4-coumarate:coenzyme a ligases in rice. Plant Physiol. 157, 574-586. doi: 10.1104/pp.111.178301

Guo, L., Devaiah, S. P., Narasimhan, R., Pan, X., Zhang, Y., Zhang, W., et al. (2012). Cytosolic glyceraldehyde-3-phosphate dehydrogenases interact with phospholipase $\mathrm{D} \delta$ to transduce hydrogen peroxide signals in the Arabidopsis response to stress. Plant Cell 24, 2200-2212. doi: 10.1105/tpc.111.094946

Hazman, M., Hause, B., Eiche, E., Nick, P., and Riemann, M. (2015). Increased tolerance to salt stress in OPDA-deficient rice allene oxide cyclase mutants is linked to an increased ROS-scavenging activity. J. Exp. Bot. 66, 3339-3352. doi: $10.1093 /$ jxb/erv142

He, Y., Mawhinney, T. P., Preuss, M. L., Schroeder, A. C., Chen, B., Abraham, L., et al. (2009). A redox-active isopropylmalate dehydrogenase functions in the biosynthesis of glucosinolates and leucine in Arabidopsis. Plant J. 60, 679-690. doi: 10.1111/j.1365-313X.2009.03990.x

Henry, A., Cal, A. J., Batoto, T. C., Torres, R. O., and Serraj, R. (2012). Root attributes affecting water uptake of rice (Oryza sativa) under drought. J. Exp. Bot. 63, 4751-4763. doi: 10.1093/jxb/ers150

Henry, A., Swamy, B. P. M., Dixit, S., Torres, R. D., Batoto, T. C., Manalili, M., et al. (2015). Physiological mechanisms contributing to the QTL-combination effects on improved performance of IR64 rice NILs under drought. J. Exp. Bot. 66, 1787-1799. doi: 10.1093/jxb/eru506

Hirano, K., Aya, K., Kondo, M., Okuno, A., Morinaka, Y., and Matsuoka, M. (2012). OsCAD2 is the major CAD gene responsible for monolignol biosynthesis in rice culm. Plant Cell Rep. 31, 91-101. doi: 10.1007/s00299-011-1142-7

Hofmann, E., Zerbe, P., and Schaller, F. (2006). The crystal structure of Arabidopsis thaliana allene oxide cyclase: insights into the oxylipin cyclization reaction. Plant Cell 18, 3201-3217. doi: 10.1105/tpc.106.043984

Jwa, N.-S., Agrawal, G. K., Tamogami, S., Yonekura, M., Han, O., Iwahashi, H., et al. (2006). Role of defense/stress-related marker genes, proteins and secondary metabolites in defining rice self-defense mechanisms. Plant Physiol. Biochem. 44, 261-273. doi: 10.1016/j.plaphy.2006.06.010

Kalamaki, M. S., Alexandrou, D., Lazari, D., Merkouropoulos, G., Fotopoulos, V., Pateraki, I., et al. (2009). Over-expression of a tomato N-acetyl-L-glutamate synthase gene (SINAGS1) in Arabidopsis thaliana results in high ornithine levels and increased tolerance in salt and drought stresses. J. Exp. Bot. 60, 1859-1871. doi: 10.1093/jxb/erp072

Kärkönen, A. (2005). Biosynthesis of UDP-GlcA: Via UDPGDH or the myo- inositol oxidation pathway? Plant Biosystems, 139, 46-49. doi: 10.1080/11263500500056161

Kärkönen, A., Murigneux, A., Martinant, J.-P., Pepey, E., Tatout, C., Dudley, B. J., et al. (2005). UDP-glucose dehydrogenases of maize: a role in cell wall pentose biosynthesis. Biochem. J. 391, 409-415. doi: 10.1042/BJ20050800

Kijoji, A. A., Nchimbi-Msolla, S., Kanyeka, Z. L., Klassen, S. P., Serraj, R., and Henry, A. (2012). Water extraction and root traits in Oryza sativa $\times$ Oryza glaberrima introgression lines under different soil moisture regimes. Funct. Plant Biol. 40, 54-66. doi: 10.1071/FP12163

Kim, B. G., Sung, S. H., Chong, Y., Lim, Y., and Ahn, J. H. (2010). Plant flavonoid O-methyltransferases: substrate specificity and application. J. Plant Biol. 53, 321-329. doi: 10.1007/s12374-010-9126-7

Kohli, A., Narciso, J. O., Miro, B., and Raorane, M. (2012). Root proteases: reinforced links between nitrogen uptake and mobilization and drought tolerance. Physiol. Plant. 145, 165-179. doi: 10.1111/j.1399-3054.2012.01573.x

Kohli, A., Sreenivasulu, N., Lakshmanan, P., and Kumar, P. P. (2013). The phytohormone crosstalk paradigm takes center stage in understanding how plants respond to abiotic stresses. Plant Cell Rep. 32, 945-957. doi: 10.1007/s00299-013-1461-y
Koshiba, T., Hirose, N., Mukai, M., Yamamura, M., Hattori, T., Suzuki, S., et al. (2013). Characterization of 5-Hydroxyconiferaldehyde O-Methyltransferase in Oryza sativa. Plant Biotechnol. 30, 157-167. doi: 10.5511/plantbiotechnology.13.0219a

Kurepa, J., Wang, S., Li, Y., and Smalle, J. (2009). Proteasome regulation, plant growth and stress tolerance. Plant Signal. Behav. 4, 924-927. doi: $10.4161 /$ psb.4.10.9469

Lackman, P., González-Guzmán, M., Tilleman, S., Carqueijeiro, I., Pérez, A. C., Moses, T., et al. (2011). Jasmonate signaling involves the abscisic acid receptor PYL4 to regulate metabolic reprogramming in Arabidopsis and tobacco. Proc. Natl. Acad. Sci. U.S.A. 108, 5891-5896. doi: 10.1073/pnas.11030 10108

Laemmli, V. (1970). Determination of protein molecular weight in polyacrylamide gels. Nature 227, 680-685. doi: 10.1038/227680a0

Lea, P. J., and Miflin, B. J. (2011). Nitrogen assimilation and its relevance to crop improvement. Annu. Plant Rev. 42, 1-40. doi: 10.1002/9781444328608

Liu, N., and Avramova, Z. (2016). Molecular mechanism of the priming by jasmonic acid of specific dehydration stress response genes in Arabidopsis. Epigenet. Chrom. 9:8. doi: 10.1186/s13072-016-0057-5

Liu, Z., Zhang, S., Sun, N., Liu, H., Zhao, Y., Liang, Y., et al. (2015). Functional diversity of jasmonates in rice. Rice 8:5. doi: 10.1186/s12284-015-0042-9

Mahdieh, M., Mostajeran, A., Horie, T., and Katsuhara, M. (2008). Drought stress alters water relations and expression of PIP-type aquaporin genes in Nicotiana tabacum plants. Plant Cell Physiol. 49, 801-813. doi: 10.1093/pcp/pcn054

Manzoni, S., Vico, G., Katul, G., Fay, P. A., Polley, W., Palmroth, S., et al. (2011). Optimizing stomatal conductance for maximum carbon gain under water stress: a meta-analysis across plant functional types and climates. Funct. Ecol. 25, 456-467. doi: 10.1111/j.1365-2435.2010.01822.x

Mitchell, J., Fukai, S., and Cooper, M. (1996). Influence of phenology on grain yield variation among barley cultivars grown under terminal drought. Aust. J. Agric. Res. 47, 757-774. doi: 10.1071/AR9960757

Mittler, R., and Blumwald, E. (2015). The roles of ROS and ABA in systemic acquired acclimation. Plant Cell 27, 64-70. doi: 10.1105/tpc.114.133090

Moons, A. (2005). "Regulatory and functional interactions of plant growth regulators and plant Glutathione S-Transferases (GSTs)," in Vitamins and Hormones, Vol. 72, ed G. Litwack (Academic Press), 155-202. doi: 10.1016/S0083-6729(05)72005-7. Available online at: http://www. sciencedirect.com/science/article/pii/S0083672905720057

Moreno, J. I., Martín, R., and Castresana, C. (2005). Arabidopsis SHMT1, a serine hydroxymethyltransferase that functions in the photorespiratory pathway influences resistance to biotic and abiotic stress. Plant J. 41, 451-463. doi: 10.1111/j.1365-313X.2004.02311.x

Mueller-Harvey, I., Hartley, R. D., Harris, P. J., and Curzon, E. H. (1986). Linkage of p-coumaroyl and feruloyl groups to cell-wall polysaccharides of barley straw. Carbohydr. Res. 148, 71-85. doi: 10.1016/0008-6215(86)80038-6

Negin, B., and Moshelion, M. (2016). The evolution of the role of ABA in the regulation of water-use efficiency: from biochemical mechanisms to stomatal conductance. Plant Sci. 251, 82-89. doi: 10.1016/j.plantsci.2016.05.007

O'Toole, T. C. (2004) "Rice water: the final frontier," in First International Conference on Rice for the Future (Bangkok).

Otto, M., Naumann, C., Brandt, W., Wasternack, C., and Hause, B. (2016). Activity regulation by heteromerization of Arabidopsis allene oxide cyclase family members. Plants 5:3. doi: 10.3390/plants5010003

Pabuayon, I. M., Yamamoto, N., Trinidad, J. L., Longkumer, T., Raorane, M. L., and Kohli, A. (2016). Reference genes for accurate gene expression analyses across different tissues, developmental stages and genotypes in rice for drought tolerance. Rice 9:32. doi: 10.1186/s12284-016-0104-7

Pedranzani, H., and Vigliocco, A. (2017). "Regulation of jasmonic acid and salicylic acid levels in abiotic stress tolerance: past and present," in Mechanisms Behind Phytohormonal Signalling and Crop Abiotic Stress Tolerance, eds V. P. Singh, S. Singh, and S. M. Prasad (New York, NY: Nova Science Publishers), 329-370.

Pomar, F., Merino, F., and Barceló, A. R. (2002). O-4-Linked coniferyl and sinapyl aldehydes in lignifying cell walls are the main targets of the Wiesner (phloroglucinol-HCl) reaction. Protoplasma 220, 17-28. doi: 10.1007/s00709-002-0030-y

Phimchan, P., Chanthai, S., Bosland, P. W., and Techawongstien, S. (2014). Enzymatic changes in phenylalanine ammonia-lyase, cinnamic-4-hydroxylase, 
capsaicin synthase, and peroxidase activities in Capsicum under drought stress. J. Agric. Food Chem. 62, 7057-7062. doi: 10.1021/jf4051717

R Core Team (2016). R: A Language and Environment for Statistical Computing. Vienna: R Foundation for Statistical Computing. Available online at: http:// www.R-project.org/

Rakszegi, M., Lovegrove, A., Balla, K., Láng, L., Bedo, Z., Veisz, O., et al. (2014). Effect of heat and drought stress on the structure and composition of arabinoxylan and $\beta$-glucan in wheat grain. Carbohydr. Polym. 102, 557-565. doi: 10.1016/j.carbpol.2013.12.005

Ramachandran, S., Christensen, H. E., Ishimaru, Y., Dong, C.-H., Chao-Ming, W., Cleary, A. L., et al. (2000). Profilin plays a role in cell elongation, cell shape maintenance, and flowering in Arabidopsis. Plant Physiol. 124, 1637-1647. doi: 10.1104/pp.124.4.1637

Raorane, M. L., Pabuayon, I. M., Miro, B., Kalladan, R., Reza-Hajirezai, M., Oane, R. H., et al. (2015b). Variation in primary metabolites in parental and near-isogenic lines of the QTL qDTY(12.1): altered roots and flag leaves but similar spikelets of rice under drought. Mol. Breed. 35:138. doi: 10.1007/s11032-015-0322-5

Raorane, M. L., Pabuayon, I. M., Varadarajan, A. R., Mutte, S. K., Kumar, A., Treumann, A., et al. (2015a). Proteomic insights into the role of the largeeffect QTL qDTY 12.1 for rice yield under drought. Mol. Breed. 35:139. doi: 10.1007/s11032-015-0321-6

Riccardi, F., Gazeau, P., de Vienne, D., and Zivy, M. (1998). Protein changes in response to progressive water deficit in maize: quantitative variation and polypeptide identification. Plant Physiol. 117, 1253-1263. doi: $10.1104 /$ pp.117.4.1253

Riemann, M., Dhakarey, R., Hazman, M., Miro, B., Kohli, A., and Nick, P. (2015). Exploring jasmonates in the hormonal network of drought and salinity responses. Front. Plant Sci. 6:1077. doi: 10.3389/fpls.2015.01077

Riemann, M., Haga, K., Shimizu, T., Okada, K., Ando, S., Mochizuki, S., et al. (2013). Identification of rice allene oxide cyclase mutants and the function of jasmonate for defence against Magnaporthe oryzae. Plant J. 74, 226-238. doi: $10.1111 /$ tpj.12115

Riquelme, A., and Hinrichsen, P. (2015). Non-symbiotic hemoglobin and its relation with hypoxic stress. Chilean J. Agric. Res. 75, 80-89. doi: 10.4067/S0718-58392015000300009

Sandhu, N., Raman, K. A., Torres, R. O., Audebert, A., Dardou, A., Kumar, A., et al. (2016). Rice root architectural plasticity traits and genetic regions for adaptability to variable cultivation and stress conditions. Plant Physiol. 171, 2562-2576. doi: 10.1104/pp.16.00705

Santner, A., and Estelle, M. (2010). The ubiquitin-proteasome system regulates plant hormone signaling. Plant J. 61, 1029-1040. doi: $10.1111 / \mathrm{j} .1365-313 X .2010 .04112 . \mathrm{x}$

Santos, A. B. D., Bottcher, A., Kiyota, E., Mayer, J. L. S., Vicentini, R., Brito, M. D. S., et al. (2015). Water stress alters lignin content and related gene expression in two sugarcane genotypes. J. Agric. Food Chem. 63, 4708-4720. doi: $10.1021 /$ jf5061858

Sasaki, Y., Asamizu, E., Shibata, D., Nakamura, Y., Kaneko, T., Awai, K., et al. (2001). Monitoring of methyl jasmonate-responsive genes in Arabidopsis by cDNA macroarray: self-activation of jasmonic acid biosynthesis and crosstalk with other phytohormone signaling pathways. DNA Res. 8, 153-161. doi: 10.1093/dnares/8.4.153

Sasaki-Sekimoto, Y., Taki, N., Obayashi, T., Aono, M., Matsumoto, F., Sakurai, N., et al. (2005). Coordinated activation of metabolic pathways for antioxidants and defence compounds by jasmonates and their roles in stress tolerance in Arabidopsis. Plant J. 44, 653-668. doi: 10.1111/j.1365-313X.2005.02560.x

Savchenko, T., Kolla, V. A., Wang, C.-Q., Nasafi, Z., Hicks, D. R., Phadungchob, B., et al. (2014). Functional convergence of oxylipin and abscisic acid pathways controls stomatal closure in response to drought. Plant Physiol. 164, 1151-1160. doi: $10.1104 /$ pp.113.234310

Schäfer, J., Wagner, S., Trierweiler, B., and Bunzel, M. (2016). Characterization of cell wall components and their modifications during postharvest storage of Asparagus officinalis L.: storage-related changes in dietary fiber composition. J. Agric. Food Chem. 64, 478-486. doi: 10.1021/acs.jafc. $5 \mathrm{~b} 05575$

Schmit, A. C., and Nick, P. (2008). "Microtubules and the evolution of mitosis," in Plant Microtubules: Development and Flexibility, ed P. Nick (Berlin, Heidelberg: Springer Berlin Heidelberg), 233-266.
Secchi, F., Lovisolo, C., and Schubert, A. (2007). Expression of OePIP2.1 aquaporin gene and water relations of Olea europaea twigs during drought stress and recovery. Ann. Appl. Biol. 150, 163-167. doi: 10.1111/j.1744-7348.2007.00118.x

Sengupta, D., Kannan, M., and Reddy, A. R. (2011). A root proteomics-based insight reveals dynamic regulation of root proteins under progressive drought stress and recovery in Vigna radiata (L.) Wilczek. Planta 233, 1111-1127. doi: 10.1007/s00425-011-1365-4

Shinozaki, K., and Yamaguchi-Shinozaki, K. (2007). Gene networks involved in drought stress response and tolerance. J. Exp. Bot. 58, 221-227. doi: $10.1093 /$ jxb/erl164

Songsri, P., Jogloy, S., Junjittakarn, J., Kesmala, T., Vorasoot, N., Holbrook, C. C., et al. (2013). Association of stomatal conductance and root distribution with water use efficiency of peanut under different soil water regimes. Austr. J. Crop Sci. 7, 948-955. Available online at: http://www.cropj.com/songsari_7_7_2013_ 948_955.pdf

Sreenivasulu, N., Harshavardhan, V. T., Govind, G., Seiler, C., and Kohli, A. (2012). Contrapuntal role of ABA: does it mediate stress tolerance or plant growth retardation under long-term drought stress? Gene 506, 265-273. doi: 10.1016/j.gene.2012.06.076

Srividhya, A., Vemireddy, L. R., Sridhar, S., Jayaprada, M., Ramanarao, P. V., Hariprasad, A. S., et al. (2011). Molecular mapping of QTLs for yield and its components under two water supply conditions in rice (Oryza sativa L.). J. Crop Sci. Biotechnol. 14, 45-56. doi: 10.1007/s12892-010-0023-x

Stenzel, I., Otto, M., Delker, C., Kirmse, N., Schmidt, D., Miersch, O., et al. (2012). ALLENE OXIDE CYCLASE (AOC) gene family members of Arabidopsis thaliana: tissue- and organ-specific promoter activities and in vivo heteromerization. J. Exp. Bot. 63, 6125-6138. doi: 10.1093/jxb/ers261

Tani, T., Sobajima, H., Okada, K., Chujo, T., Arimura, S., Tsutsumi, N., et al. (2007). Identification of the OsOPR7 gene encoding 12-oxophytodienoate reductase involved in the biosynthesis of jasmonic acid in rice. Planta 227:517. doi: 10.1007/s00425-007-0635-7

Thimm, O., Bläsing, O., Gibon, Y., Nagel, A., Meyer, S., Krüger, P., et al. (2004). MAPMAN: a user-driven tool to display genomics data sets onto diagrams of metabolic pathways and other biological processes. Plant J. 37, 914-939. doi: 10.1111/j.1365-313X.2004.02016.x

Tuteja, N. (2007). Abscisic acid and abiotic stress signaling. Plant Signal. Behav. 2, 135-138. doi: 10.4161/psb.2.3.4156

Urbanowicz, B. R., Peña, M. J., Ratnaparkhe, S., Avci, U., Backe, J., Steet, H. F., et al. (2012). 4-O-methylation of glucuronic acid in Arabidopsis glucuronoxylan is catalyzed by a domain of unknown function family 579 protein. Proc. Natl. Acad. Sci. U.S.A. 109, 14253-14258. doi: 10.1073/pnas.1208097109

Venuprasad, R., Cruz, M. S., Amante, M., Magbanua, R., Kumar, A., and Atlin, G. (2008). Response to two cycles of divergent selection for grain yield under drought stress in four rice breeding populations. Field Crops Res. 107, 232-244. doi: 10.1016/j.fcr.2008.02.004

Vig, A. P., Rampal, G., Thind, T. S., and Arora, S. (2009). Bio-protective effects of glucosinolates - a review. LWT Food Sci. Technol. 42, 1561-1572. doi: 10.1016/j.lwt.2009.05.023

Vigeolas, H., Hühn, D., and Geigenberger, P. (2011). Nonsymbiotic Hemoglobin2 leads to an elevated energy state and to a combined increase in polyunsaturated fatty acids and total oil content when overexpressed in developing seeds of transgenic Arabidopsis plants. Plant Physiol. 155, 1435-1444. doi: 10.1104/pp.110.166462

Vincent, D., Lapierre, C., Pollet, B., Cornic, G., Negroni, L., and Zivy, M. (2005). Water deficits affect caffeate o-methyltransferase, lignification, and related enzymes in maize leaves. A proteomic investigation. Plant Physiol. 137, 949-960. doi: 10.1104/pp.104.050815

Wakabayashi, K., Hoson, T., and Kamisaka, S. (1997a). Osmotic stress suppresses cell wall stiffening and the increase in cell wall-bound ferulic and diferulic acids in wheat coleoptiles. Plant Physiol. 38, 811-817.

Wakabayashi, K., Hoson, T., and Kamisaka, S. (1997b). Abscisic acid suppresses the increases in cell wall-bound ferulic and diferulic acid levels in dark-grown wheat (Triticum aestivum L.) coleoptiles. Plant Cell Physiol. 113, 967-973.

Wang, Y., Li, X., Guo, K., Peng, L., and Wang, Y. (2017). Gene profiling of plant cell wall biosynthesis for genetic enhancing biomass enzymatic saccharificationin cereal crops. J. Plant Biochem. Physiol. 5:2. doi: 10.4172/2329-9029.1000179

Wassmann, R., Jagadish, S. V. K., Heuer, S., Ismail, A., Redona, E., Serraj, R., et al. (2009). "Climate change affecting rice production: the 
physiological and agronomic basis for possible adaptation strategies," in Advances in Agronomy, Vol. 101, ed L. D. Sparks (Academic Press), 59-122. doi: 10.1016/S0065-2113(08)00802-X. Available online at: http://www.sciencedirect.com/science/article/pii/S006521130800802X

Wasternack, C. (2007). Jasmonates: an update on biosynthesis, signal transduction and action in plant stress response, growth and development. Ann. Bot. 100, 681-697. doi: 10.1093/aob/mcm079

Wasternack, C., and Hause, B. (2013). Jasmonates: biosynthesis, perception, signal transduction and action in plant stress response, growth and development. Ann. Bot. 111, 1021-1058. doi: 10.1093/aob/mct067

Wolters, H., and Jurgens, G. (2009). Survival of the flexible: hormonal growth control and adaptation in plant development. Nat. Rev. Genet. 10, 305-317. doi: $10.1038 / \mathrm{nrg} 2558$

Xu, X. M., Lin, H., Maple, J., Björkblom, B., Alves, G., Larsen, J. P., et al. (2010). The Arabidopsis DJ-1a protein confers stress protection through cytosolic SOD activation. J. Cell Sci. 123:1644. doi: 10.1242/jcs.063222

Yan, Y., Christensen, S., Isakeit, T., Engelberth, J., Meeley, R., Hayward, A., et al. (2012). Disruption of OPR7 and OPR8 reveals the versatile functions of jasmonic acid in maize development and defense. Plant Cell 24, 1420-1436. doi: 10.1105/tpc.111.094151

Yoon, J., Choi, H., and An, G. (2015). Roles of lignin biosynthesis and regulatory genes in plant development. J. Integr. Plant Biol. 57, 902-912. doi: $10.1111 /$ jipb. 12422

Yoshimura, K., Masuda, A., Kuwano, M., Yokota, A., and Akashi, K. (2008). Programmed proteome response for drought avoidance/tolerance in the root of a C3 xerophyte (wild watermelon) under water deficits. Plant Cell Physiol. 49, 226-241. doi: 10.1093/pcp/pcm 180
Zabalza, A., van Dongen, J. T., Froehlich, A., Oliver, S. N., Faix, B., Gupta, K. J., et al. (2009). Regulation of respiration and fermentation to control the plant internal oxygen concentration. Plant Physiol. 149, 1087-1098. doi: 10.1104/pp.108.129288

Zhang, J., and Davies, W. J. (1990). Changes in the concentration of ABA in xylem sap as a function of changing soil water status can account for changes in leaf conductance and growth. Plant Cell Environ. 13, 277-285. doi: 10.1111/j.1365-3040.1990.tb01312.x

Zhao, Q., and Dixon, R. A. (2011). Transcriptional networks for lignin biosynthesis: more complex than we thought? Trends Plant Sci. 16, 227-233. doi: 10.1016/j.tplants.2010.12.005

Zhao, Z., Liu, H., Luo, Y., Zhou, S., An, L., Wang, C., et al. (2014). Molecular evolution and functional divergence of tubulin superfamily in the fungal tree of life. Sci. Rep. 4:6746. doi: 10.1038/srep 06746

Conflict of Interest Statement: The authors declare that the research was conducted in the absence of any commercial or financial relationships that could be construed as a potential conflict of interest.

Copyright (c) 2017 Dhakarey, Raorane, Treumann, Peethambaran, Schendel, Sahi, Hause, Bunzel, Henry, Kohli and Riemann. This is an open-access article distributed under the terms of the Creative Commons Attribution License (CC BY). The use, distribution or reproduction in other forums is permitted, provided the original author(s) or licensor are credited and that the original publication in this journal is cited, in accordance with accepted academic practice. No use, distribution or reproduction is permitted which does not comply with these terms. 